\title{
Psychosocial recommendations for the care of children and adults with epidermolysis bullosa and their family: evidence based guidelines
}

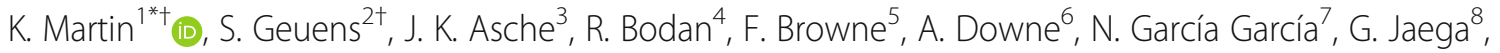

B. Kennedy ${ }^{5}$, P. J. Mauritz ${ }^{9}$, F. Pérez ${ }^{10}$, K. Soon ${ }^{11}$, V. Zmazek ${ }^{12}$ and K. M. Mayre-Chilton ${ }^{6,13}$

\begin{abstract}
Epidermolysis Bullosa (EB) is a group of rare genetic disorders resulting in skin fragility and other symptoms. Commissioned by DEBRA International and funded by DEBRA Norway, this evidence-bases guideline provides recommendations to optimise psychosocial wellbeing in EB.

An international multidisciplinary panel of social and health care professionals (HCP) and people living with EB was formed. A systematic international literature review was conducted by the panel following the Scottish Intercollegiate Guidelines Network (SIGN) methodology. The resulting papers underwent systematic selection and critique processes. Included papers were allocated to 6 different outcome groups to allow data synthesis and exploration: quality of life, coping, family, wellbeing, access to HCP and pain. Based on the evidence in those papers, recommendations were made for individuals living with EB, family and caregivers and HCP working in the field.

Few studies have investigated interventions and which factors lead to better outcomes, but general recommendations can be made. EB is a complex disease impacting enormously on every aspect of psychosocial life. People and families living with EB need access to multidisciplinary support, including psychological guidance, in order to improve quality of life and psychosocial wellbeing. Interventions should stimulate social participation to prevent isolation. People with EB and their families should be able to access a supportive network. HCP should be well supported and educated about the complexity of EB. They should work collaboratively with those around the individual with EB (e.g. schools, employers etc.) to provide psychosocial opportunity and care.

Attention should be paid to the psychosocial impact of EB as well as physical needs. Directions for research are indicated.
\end{abstract}

Keywords: Epidermolysis bullosa, Psychosocial, Guideline, Recommendations, Psychological, Social, Family, Professionals

\section{Introduction}

Epidermolysis Bullosa (EB) is a group of rare genetic disorders, the primary manifestation is the formation of blisters and erosions in response to mechanical trauma [1]. While there are currently over 30 known subtypes of $E B$, there are four primary types including EB Simplex (EBS), Dystrophic EB (DEB), Junctional EB (JEB), and Kindler syndrome (KS) $[1,2]$. EB can be the result of

\footnotetext{
* Correspondence: office@debra-international.org

${ }^{+} \mathrm{K}$. Martin and S. Geuens contributed equally to this work.

'University Hospitals Birmingham NHS Trust, Solihull Hospital, Solihull, B91 2JL, UK

Full list of author information is available at the end of the article
}

either inherited or spontaneous dominant mutations, as seen in most forms of EBS and Dominant DEB (DDEB); or from inherited recessive mutations as in rare forms of EBS, Recessive DEB (RDEB), JEB, and KS [2].

The severity and scope of EB varies widely by type and subtype. The mildest forms of EBS and DDEB may be limited to localised bullae (blisters) and wounds which can be very painful, impacting quality of life (QoL) [1]. More severe forms of EBS, RDEB, and JEB can result in generalised bullae and erosions, with significant extracutaneous involvement, which may require the care of a large multidisciplinary team. Potential complications of more severe EB include, but are not limited to, sepsis, anaemia, failure

(c) The Author(s). 2019 Open Access This article is distributed under the terms of the Creative Commons Attribution 4.0 International License (http://creativecommons.org/licenses/by/4.0/), which permits unrestricted use, distribution, and reproduction in any medium, provided you give appropriate credit to the original author(s) and the source, provide a link to the Creative Commons license, and indicate if changes were made. The Creative Commons Public Domain Dedication waiver (http://creativecommons.org/publicdomain/zero/1.0/) applies to the data made available in this article, unless otherwise stated. 
to thrive, pseudosyndactyly, contractures, and squamous cell carcinoma [3-12]. Average life expectancy for those with severe RDEB is about 30 years of age [13]. With the exception of infant mortality, seen in rare cases of EBS, and more commonly in JEB, life expectancy is thought to be unaffected in other forms of EB $[4,6]$.

Currently there is no cure for EB; all known treatments at this point are experimental. The mainstay of EB management continues to be supportive in nature, with symptom control and wound care at the centre. Wound care can be a very painful and lengthy process, lasting up to several hours a session, done daily or every other day for most patients [14]. As a result of the time it takes to care for the medical needs and the pain and discomfort that is inherent with the condition, EB can significantly impact all domains of a patient and family's life. This includes interactions with family, friends, and peers, education, employment and leisure time [15-17]. Due to the profound impact of $E B$, it is understandable that many individuals living with EB may struggle with physiological suffering and psychosocial sequelae.

Psychosocial health is a broad term defined by the American Psychological Association as describing the intersection and interaction of social, cultural and environmental influences on the mind and behaviour' [18]. Whilst some individuals will be able to successfully navigate their lives without psychosocial intervention or assistance from the health care team, many would likely benefit from assessment and intervention. Unfortunately, at this time, there is little in the way of guidance for clinicians regarding how to best care for the psychosocial health of patients and families affected by EB. When we consider the extent to which their lives can be affected, and the impact that psychosocial health can have on one's physical health, this is a pressing need for those in the EB community.

DEBRA International (DI) therefore sponsored the development of psychosocial clinical practice guidelines (CPGs) for individuals and families living with EB. In 2016 an expert panel was convened by DI comprising clinicians from several countries with expertise related to social care and mental health and EB, people living with EB and family members from the international EB community.

An extensive systematic literature search and synthesis was conducted by the expert panel. Based on the synthesis of the literature and priorities raised by the EB community, six outcomes were found to be relevant with regards to the psychosocial health of those affected by EB: QoL, coping, family, well-being, access to health care professionals (HCPs) and pain. Whilst the concepts of QoL, coping and well-being are complex with many interpretations and some overlap, the expert panel agreed on the following published definitions for each of these three concepts:
* QoL: defined as an 'individual's perception of their position in life, in the context of the culture and value systems in which they live and in relation to their goals, expectations, standards and concerns. It is a broad ranging concept affected in a complex way by the person's physical health, psychological state, level of independence, social relationships, personal beliefs and their relationship to salient features of their environment' [19].

* Coping: defined as 'thoughts and behaviours that people use to respond to internal or external stressful demands' [20].

* Well-being: defined as the "balance point between an individual's resource pool and the challenges faced' [21].

An evidence-based discussion of the impact of EB on QoL, coping, family, well-being, access to HCPs and pain follows. The synthesis and discussion include suggestions for potential prevention, intervention strategies and suggestions for future research.

\section{Objectives of the CPG}

- Provide guidance on the psychosocial needs of people with EB, their families and those who care for them.

* Outline the current state of the science on the psychosocial implications of EB on patients and their family members.

* Include recommendations for care.

* Identify gaps in knowledge to encourage future research.

Users These guidelines are intended for professionals working to help those living with EB, employers, teachers, stakeholders and policy makers. They are for those who care for people with EB (all types) and their families.

\section{Target groups}

$\star$ Professionals caring for EB patients and their families.

* EB patients of all ages and diagnosed with any of the four major types of EB: EB Simplex, Junctional EB, Dystrophic EB and Kindler Syndrome.

* Families of people with EB.

\section{Methods}

The expert panel of multidisciplinary HCPs and people living with EB was co-ordinated through Debra International (DI) through a voluntary membership. The international panel represented clinical, social or personal experience of EB covering both adult and paediatric knowledge (Additional file 1. shows panel membership). 
The panel voted for their clinical representative (indicated here as the first two authors, chair and co-chair). During the development of the CPG two people living with EB and four HPCs had to resign from their roles due to changes in commitments or conflict of interest (CoI). Two new HCPs were accepted on to the panel. Panel members were encouraged to be involved in all stages of the CPG development (Additional file 1).

Following the Scottish Intercollegiate Guidelines Network [22] (SIGN) methodology, the panel decided on the research question "Can psychosocial support help people to cope with EB?" The concepts of QoL, cope and well-being were defined to help the panel and analyses of the literature. The focus of the project was decided by considering the relevant "PICOs" (Fig. 1): Participants were the target populations, Interventions was to have psychosocial support or psychotherapy or social worker support, Compared to not having this support available, Outcomes and study design. These terms were informed by: priorities raised by people living with EB in a focus group conducted at the Croatia DI Congress 2016; a preliminary literature search conducted by a $\mathrm{PhD}$ study and presentation from an expert in the field [23]; and further discussion about the meaning of "psychosocial" and "cope" amongst the panel.

\section{Literature search process}

Preliminary guideline database searches were undertaken in 2016: https://www.ahrq.gov/gam/updates/index.html; www.g-i-n.net; www.clinicaltrials.gov and SIGN [22]. Eight guidelines in other rare conditions were identified. There were no EB guidelines covering psychosocial care.

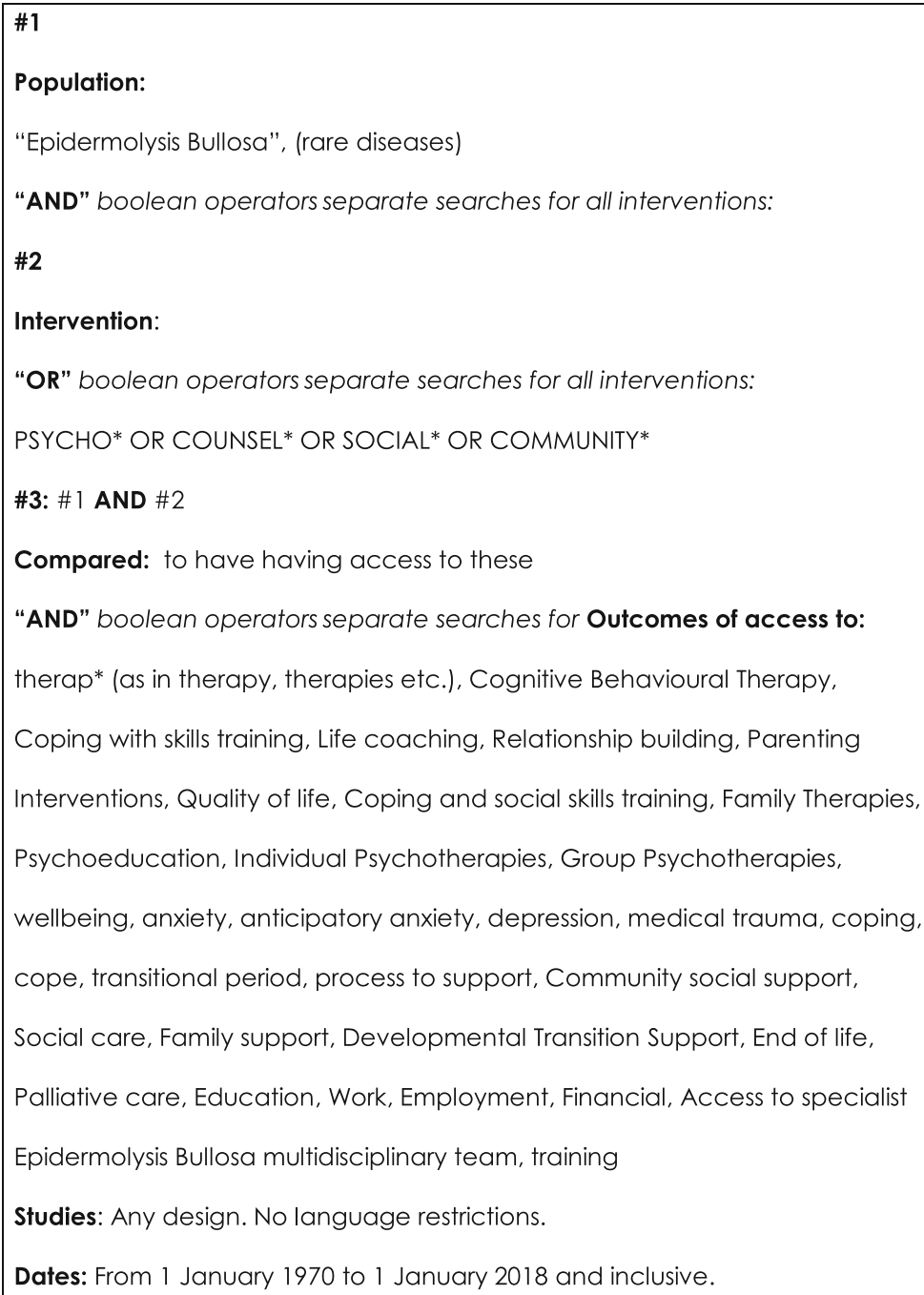

Fig. 1 Search terms and inclusion criteria 
A systematic literature search regime was conducted by librarians and nine of the panel members. Twelve electronic search engines were accessed: Medline (PubMed MeSH), Embase Emtree PsychInfo, CINHAL, Scopus, Dialnet, Google academic, British Nursing Index, Health management Information consortium (HMIC), Allied and complementary medicine (AMED),
Health business elite and the main search engine for the National Institute for Health and Care Excellence (NICE). Figure 1 shows the search terms, inclusion criteria utilising PICOS, and the boolean AND and OR operators used to combine these terms as appropriate. Terms were kept broad, translated and searched for in all engines (Fig. 2).

\begin{tabular}{|c|c|c|c|}
\hline English & Spanish & Dutch/ Flemish & French \\
\hline $\begin{array}{l}\text { 'epidermolysis } \\
\text { bullosa' AND } \\
\text { 'Psychological' }\end{array}$ & $\begin{array}{l}\text { Epidermólisis Bullosa } \\
\text { y Psicológico }\end{array}$ & $\begin{array}{l}\text { Epidermolysis Bullosa en } \\
\text { Psychologisch }\end{array}$ & $\begin{array}{l}\text { Epidermolyse bulleuse et } \\
\text { psychologique ' }\end{array}$ \\
\hline $\begin{array}{l}\text { 'epidermolysis } \\
\text { bullosa' AND } \\
\text { 'Psychologist' }\end{array}$ & $\begin{array}{l}\text { Epidermólisis Bullosa } \\
\text { y Psicólogo }\end{array}$ & $\begin{array}{l}\text { EpidermolysisBullosa en } \\
\text { Psycholoog }\end{array}$ & $\begin{array}{l}\text { "Épidermolyse bulleuse» } \\
\text { et «psychologue» }\end{array}$ \\
\hline $\begin{array}{l}\text { 'epidermolysis } \\
\text { bullosa' AND } \\
\text { 'Psychotherapist' }\end{array}$ & $\begin{array}{l}\text { Epidermólisis Bullosa } \\
\text { y psicoterapeuta }\end{array}$ & $\begin{array}{l}\text { Epidermolysis Bullosa en } \\
\text { Psychotherapeut }\end{array}$ & $\begin{array}{l}\text { "Épidermolyse bulleuse» } \\
\text { et «psychothérapeute» }\end{array}$ \\
\hline $\begin{array}{l}\text { 'epidermolysis } \\
\text { bullosa' AND } \\
\text { 'Psycho*' }\end{array}$ & $\begin{array}{l}\text { Epidermólisis Bullosa } \\
\text { y Psico }\end{array}$ & $\begin{array}{l}\text { Epidermoysis Bullosa en } \\
\text { Psycho }\end{array}$ & $\begin{array}{l}\text { 'Epidermolyse bullosa' et } \\
\text { 'Psycho*' }\end{array}$ \\
\hline $\begin{array}{l}\text { 'epidermolysis } \\
\text { bullosa' AND } \\
\text { 'Counselling' }\end{array}$ & $\begin{array}{l}\text { Epidermólisis Bullosa } \\
\text { y Asesoramiento }\end{array}$ & $\begin{array}{l}\text { Epidermolysis Bullosa en } \\
\text { Begeleiding }\end{array}$ & $\begin{array}{l}\text { 'Épidermolyse bulleuse' et } \\
\text { 'Counseling' }\end{array}$ \\
\hline $\begin{array}{l}\text { 'epidermolysis } \\
\text { bullosa' AND } \\
\text { 'Counsellor' }\end{array}$ & $\begin{array}{l}\text { Epidermólisis Bullosa } \\
\text { y Asesor }\end{array}$ & $\begin{array}{l}\text { Epidermolysis Bullosa en } \\
\text { Begeleider }\end{array}$ & $\begin{array}{l}\text { "Épidermolyse bulleuse» } \\
\text { et «conseillen» }\end{array}$ \\
\hline $\begin{array}{l}\text { 'epidermolysis } \\
\text { bullosa' AND } \\
\text { 'Psychosocial' }\end{array}$ & $\begin{array}{l}\text { Epidermólisis Bullosa } \\
\text { y Psicosocial }\end{array}$ & $\begin{array}{l}\text { Epidermolysis Bullosa en } \\
\text { Psychosociaal }\end{array}$ & $\begin{array}{l}\text { 'Épidermolyse bulleuse' et } \\
\text { 'psychosocial' }\end{array}$ \\
\hline $\begin{array}{l}\text { 'epidermolysis } \\
\text { bullosa' AND 'Social } \\
\text { support' }\end{array}$ & $\begin{array}{l}\text { Epidermólisis Bullosa } \\
\text { y apoyo social }\end{array}$ & $\begin{array}{l}\text { Epidermolysis Bullosa en } \\
\text { Sociale Steun }\end{array}$ & $\begin{array}{l}\text { «L'épidermolyse bulleuse»" } \\
\text { et le «soutien social» } \\
\text { «Epidermolyse bulleuse» }\end{array}$ \\
\hline $\begin{array}{l}\text { 'epidermolysis } \\
\text { bullosa' AND 'Social } \\
\text { worker' }\end{array}$ & $\begin{array}{l}\text { Epidermólisis Bullosa } \\
\text { y trabajador social }\end{array}$ & $\begin{array}{l}\text { Epidermolysis Bullosa en } \\
\text { Maatschappelijk werker }\end{array}$ & et «Travailleur social») \\
\hline $\begin{array}{l}\text { 'epidermolysis } \\
\text { bullosa' AND } \\
\text { 'Community support }\end{array}$ & $\begin{array}{l}\text { - Epidermólisis } \\
\text { Bullosa y apoyo } \\
\text { comunitario }\end{array}$ & $\begin{array}{l}\text { Epidermolysis Bullosa en } \\
\text { Maatschappelijke hulp }\end{array}$ & $\begin{array}{l}\text { 'Epidermolyse bulleuse' et } \\
\text { 'Soutien communautaire }\end{array}$ \\
\hline
\end{tabular}

Fig. 2 Translated Key search terms 
Cited reference searches were conducted on eligible papers. Ongoing search re-runs were continued up to 1st July 2018. Every member of the panel conducted the filtration step and research appraisal. All articles meeting the criteria for appraisal were included (Additional file 2 copy of filtration and appraisal tool). The flowchart illustrates the inclusion filters applied to all articles identified by the searches (Fig. 3). These filters were discerned from each paper's abstract and title and, in cases of uncertainty, through KM and SG examining the full articles. One paper in German was filtered by a German speaking volunteer through DI. Articles not meeting the criteria were excluded.

Book chapters, abstracts, presentations and papers which were unpublished or did not meet the methodological filters were retained as gray literature. These were examined to provide context or consider divergence within the main recommendations. Four additional articles were recommended through the review process, these were screened and 3 were excluded as they did not meet the criteria of inclusion.

\section{Language}

Any language will be included

\section{Participants}

Are the main participants:

- patients with EB?

- family of patients with EB?

- caregivers of patients with

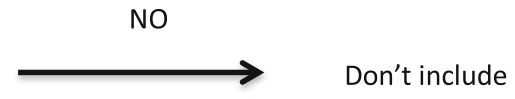
EB in any context?

- Mixed-groups (minimum 1 EB-patient)?

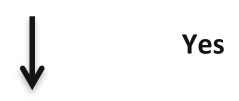

\section{Methodology}

Is the research design:

- A metareview?

- A review?

NO

- A clinical trail?

- An explorative study?

- A case report?

- A observation study?

- An expert opinion?

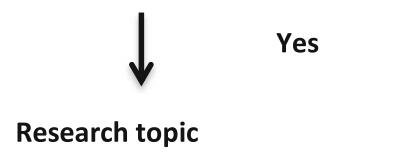

Is the research topic related to one of the terms in the yellow boxes of the Excelsheet:

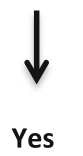

Is the topic to your

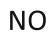
opinion relevant for $\longrightarrow$ psychosocial care in EB? Include for appraisal
Don't include

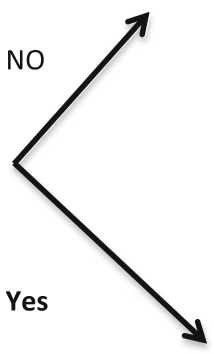

Include for appraisal and specify topic in "others"

Fig. 3 Flow-chart to filter articles based on title and abstract 


\section{Research appraisal}

All published papers meeting the filters were then subject to a systematic quality appraisal and risk of bias assessment. The appraisal tool (Additional file 2 copy of filtration and appraisal tool) was modified from the Critical Appraisal Skills Programme [24] tools, GRADE [25] tools and a quality assessment framework [26]. This allowed both quantitative and qualitative research to be appraised using one list of questions, yielding one quality rating scale to allow a comparison of studies as required. The precision and statistical consistency could not be evaluated as the EB articles had no statistical values. In most cases there was more than $50 \%$ risk of bias as it is a rare condition; there are no double blind randomised clinical studies and most participants would know they have EB. Study limitations were taken into account through the appraisal tool.

Each paper was appraised by two panel members to ensure consistency and a research quality score was obtained; the higher the value the better the quality of the paper. To prevent biases and promote reliability, precautions were taken; in cases where a panel member had authored a paper this was reviewed by other members of the panel. The level of bias was also measured in percentage values following GRADE [25] (Additional file 2) and all papers were graded in accordance to SIGN [22] method "Level of evidence and Grades of Recommendations" 1++ to 4 and Grade A to D. In cases of disagreement a third appraiser KM or SG was assigned, and uncertainty resolved.

The papers were then divided into outcome topics. These were identified through the panel ranking the outcomes' relative importance anonymously using an online survey (doodle.com), based on the Grading of Recommendations Assessment Development and Evaluation [25] (GRADE). These outcomes provided the focus of the guideline: QoL, well-being, cope, pain (management), family (support or counselling) and HCPs (access to service or support.

Some papers related to more than one outcome, so were included in all that were relevant. Two or more panel members focused on an outcome and summarised all relevant papers. They presented the emerging evidence and discussed the recommendations elicited at a meeting held in Salzburg at EB-CLINET 2017. This summary addressed: what were the recommendations emerging from the appraised research? What was the quality of the research? Were there any gaps in this research? Did the gray literature on this outcome support the emerging recommendations or suggest something different? What was the level of agreement of the members summarising the papers on this outcome? Outcome summary tables were presented to highlight the population subtypes, numbers of subjects, type of study, percentage quality and risk of bias and in accordance to SIGN [22] method "Level of evidence and Grades of Recommendations" $1++$ to 4 of the papers for each outcome.
The panel rated the strength of each recommendation, the percentage bias, desires and undesired effects, costs related to benefits and its feasibility to implement. The GRADE [25] framework tool for recommendations was completed to standardise the wording used to formulate recommendations for each outcome. Summaries were circulated to the panel and final feedback was included.

Best practice points were identified and intended to assist guideline users by providing short pieces of advice which are seen as essential to good clinical practice [25]. The Appraisal of Guidelines for Research \& Evaluation (AGREE) II tool [27] was consulted to increase the quality of practice guidelines in rare diseases and this CPG acknowledges existing guidelines by signposting with the symbol $\Rightarrow$ through this manuscript.

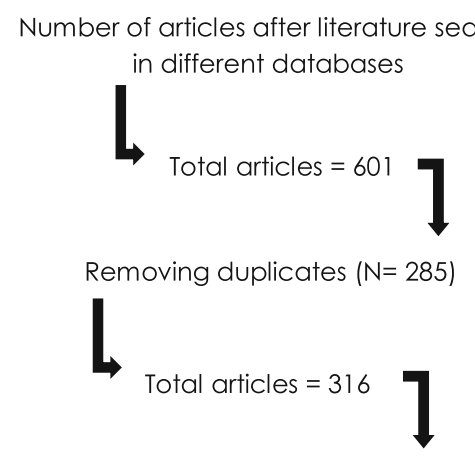

Removing articles that not meet the selection criteria in figure $3(N=181)$

L

Total articles $=135$

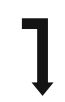

Removing articles that did not pass the appraisal process ( $\mathrm{N}=102)$

$\rightarrow$

Total articles $=33$

Additional articles up to June 2018 or

Total articles $=40 \quad$ suggested through the

L

Removing articles that did not pass the filtration or appraisal process

$$
\begin{gathered}
(\mathrm{N}=4) \\
\text { Total articles }=36 \\
\text { cation to the differ } \\
\text { outcomes }
\end{gathered}
$$$$
\rightarrow
$$

Allocation to the different

Fig. 4 Flow of information through the evidence evaluation process 
Twenty-three expert independent referees were invited to review the CPG, 11 signed a roles and responsibility agreement and $\mathrm{CoI}$ forms prior to the anonymised manuscript being circulated. The inclusion of experts from the EB community reflected the multi-disciplinary and international nature of the guideline (Additional file 1 shows author and reviewer panels). Reviewers were asked to comment primarily on the comprehensiveness and accuracy of the interpretation of the evidence base supporting the recommendations, and on how this fitted with their experiences. They were given 6 weeks to do this. This process of review is in accordance with SIGN [22]. The chair and co-chair discussed the reviewers' feedback with the guideline panel: except for the two authors who had originally declared a CoI. Each point was addressed and changes made; if no change was made, the reason for this was recorded. The panel conducted a final proof read of the manuscript before submission.

\begin{tabular}{|c|c|c|c|c|c|c|}
\hline Outcome & $\begin{array}{l}\text { Number } \\
\text { allocated } \\
\text { papers }\end{array}$ & Population & Methodology & $\begin{array}{l}\text { Average } \\
\text { quality }\end{array}$ & $\begin{array}{l}\text { Quality } \\
\text { appraisal } \\
\text { (range) }\end{array}$ & $\begin{array}{l}\text { Overall } \\
\text { consideration, } \\
\text { limitations and } \\
\text { benefits }\end{array}$ \\
\hline QoL & 15 & $\begin{array}{l}\text { Total*: } 648 \\
\text { All types**: } 12 \\
\text { RDEB**: } 2\end{array}$ & $\begin{array}{l}\text { Qualitative: } 7 \\
\text { Quantitative: } 4 \\
\text { Cohort-study: } 1 \\
\text { Systematic } \\
\text { review: } 2 \\
\text { Expert opinion: } 1\end{array}$ & $2++$ & $\begin{array}{l}65 \% \\
(33-92 \%)\end{array}$ & $\begin{array}{l}\text { Similar findings of } \\
\text { measures and the } \\
\text { need to measure QoL. } \\
\text { Mostly explorative } \\
\text { studies, no } \\
\text { interventional ones. }\end{array}$ \\
\hline Cope & 11 & $\begin{array}{l}\text { Total*: } 549 \\
\text { All types**: } 6 \\
\text { RDEB**: } 2 \\
\text { EBS**: } 2\end{array}$ & $\begin{array}{l}\text { Qualitative: } 6 \\
\text { Quantitative: } 3 \\
\text { Systematic } \\
\text { review: 1 } \\
\text { Case control } \\
\text { design: 1 }\end{array}$ & $2+$ & $\begin{array}{l}65 \% \\
(15-90 \%)\end{array}$ & $\begin{array}{l}\text { Most studies focused } \\
\text { on children with EB }\end{array}$ \\
\hline Family & 9 & $\begin{array}{l}\text { Total }^{*}: 558 \\
\text { All types**: } 8 \\
\text { RDEB**: } 1\end{array}$ & $\begin{array}{l}\text { Qualitative: } 6 \\
\text { Quantitative: } 2 \\
\text { Cohort-study: } 1\end{array}$ & $2-$ & $\begin{array}{l}75 \% \\
(33-90 \%)\end{array}$ & $\begin{array}{l}\text { Most of these studies } \\
\text { were explorative. Only } \\
\text { two studies looked at } \\
\text { interventions to support } \\
\text { the family. }\end{array}$ \\
\hline Wellbeing & 10 & $\begin{array}{l}\text { Total*: } 358 \\
\text { All types**: } 5 \\
\text { EBS, JEB, RDEB, } \\
\text { DDEB**: } 2 \\
\text { EBS, JEB, RDEB**: } 1 \\
\text { DDEB, RDEB**: } 1 \\
\text { EBS**: } 1\end{array}$ & $\begin{array}{l}\text { Qualitative: } 5 \\
\text { Quantitative: } 1 \\
\text { Mixed: } 1 \\
\text { Cohort-study: } 1 \\
\text { Expert opinion: } 2\end{array}$ & $2-$ & $\begin{array}{l}75 \% \\
(45-85 \%)\end{array}$ & $\begin{array}{l}\text { Most of the studies } \\
\text { were explorative. There } \\
\text { were no interventions } \\
\text { investigated, but } \\
\text { suggestions for } \\
\text { interventions were } \\
\text { made. }\end{array}$ \\
\hline $\begin{array}{l}\text { Access to } \\
\text { Psychoso } \\
\text { cial HCP }\end{array}$ & 8 & $\begin{array}{l}\text { Total }^{*}: 87 \\
\text { All types**: } 4 \\
\text { RDEB**: } 2 \\
\text { JEB**: } 1 \\
\text { DDEB, JEB**: } 1\end{array}$ & $\begin{array}{l}\text { Qualitative: } 4 \\
\text { Quantitative: } 1 \\
\text { Mixed: } 1 \\
\text { Cohort-study: } 1 \\
\text { Case study: } 1\end{array}$ & $2-$ & $\begin{array}{l}70 \% \\
(43-81 \%)\end{array}$ & $\begin{array}{l}\text { While one study } \\
\text { incorporated } \\
\text { standardised measures } \\
\text { and one standardised } \\
\text { projective tests, } 5 \\
\text { developed their own } \\
\text { interview/survey } \\
\text { schedules. All } \\
\text { indicated benefits to } \\
\text { this access. }\end{array}$ \\
\hline Pain & 8 & $\begin{array}{l}\text { Total: } 578 \\
\text { All types: } 6 \\
\text { DDEB: } 1 \\
\text { EBS: } 1\end{array}$ & $\begin{array}{l}\text { Qualitative: } 5 \\
\text { Quantitative: } 3\end{array}$ & $2-$ & $\begin{array}{l}62 \% \\
(38-90 \%)\end{array}$ & $\begin{array}{l}\text { Mostly explorative } \\
\text { studies. Recent studies } \\
\text { improved the quality. } \\
\text { Most were focused on } \\
\text { children, } 2 \text { on parents. } \\
\text { All indicated benefits } \\
\text { to addressing pain. }\end{array}$ \\
\hline \multicolumn{7}{|c|}{$\begin{array}{l}\text { Key: *total number of persons with EB all papers combined; **total number of papers about this type EB; EB: Epidermolysis Bullosa; } \\
\text { RDEB: Recessive Dystrophic Epidermolysis Bullosa; JEB: Junctional Epidermolysis Bullosa; DDEB: Dominant Dystrophic Epidermolysis } \\
\text { Bullosa; EBS: Epidermolysis Bullosa Simplex; EBS-I: Localised form of EBS; KS Kindler Syndrome; QoL: quality of life; HCP: Health care } \\
\text { professional }\end{array}$} \\
\hline
\end{tabular}

Fig. 5 Overview evidence per outcome 


\section{Results}

A total of 34 articles were eligible for inclusion in the final review. Figure 4 shows the flow of data through the stages of the search, filtering and appraisal process.

These papers were then allocated to the six different outcomes: Fig. 5 gives an overview of the selected articles after the appraisal process and the allocation to each outcome. QoL was the outcome with the most allocated papers $(n=$ 15 ) and Access to HCPs and Pain had the least $(n=8)$. Furthermore, Fig. 5 shows the overall number of participants, and the number of people with different types of $E B$, in the papers allocated to each outcome. It describes their methodologies and the average quality of the papers per outcome. Finally, it demonstrates the average score (and range) on the appraisal criteria and a brief general consideration, limitations and benefits per outcome.

\section{Recommendations}

The recommendations are outlined and discussed within the context of professionals providing A. psychosocial care for the individual with EB, B. psychosocial care for the family and caregiver, then C. self-care for professionals working with those affected by EB (Tables 1, 2 and 3).

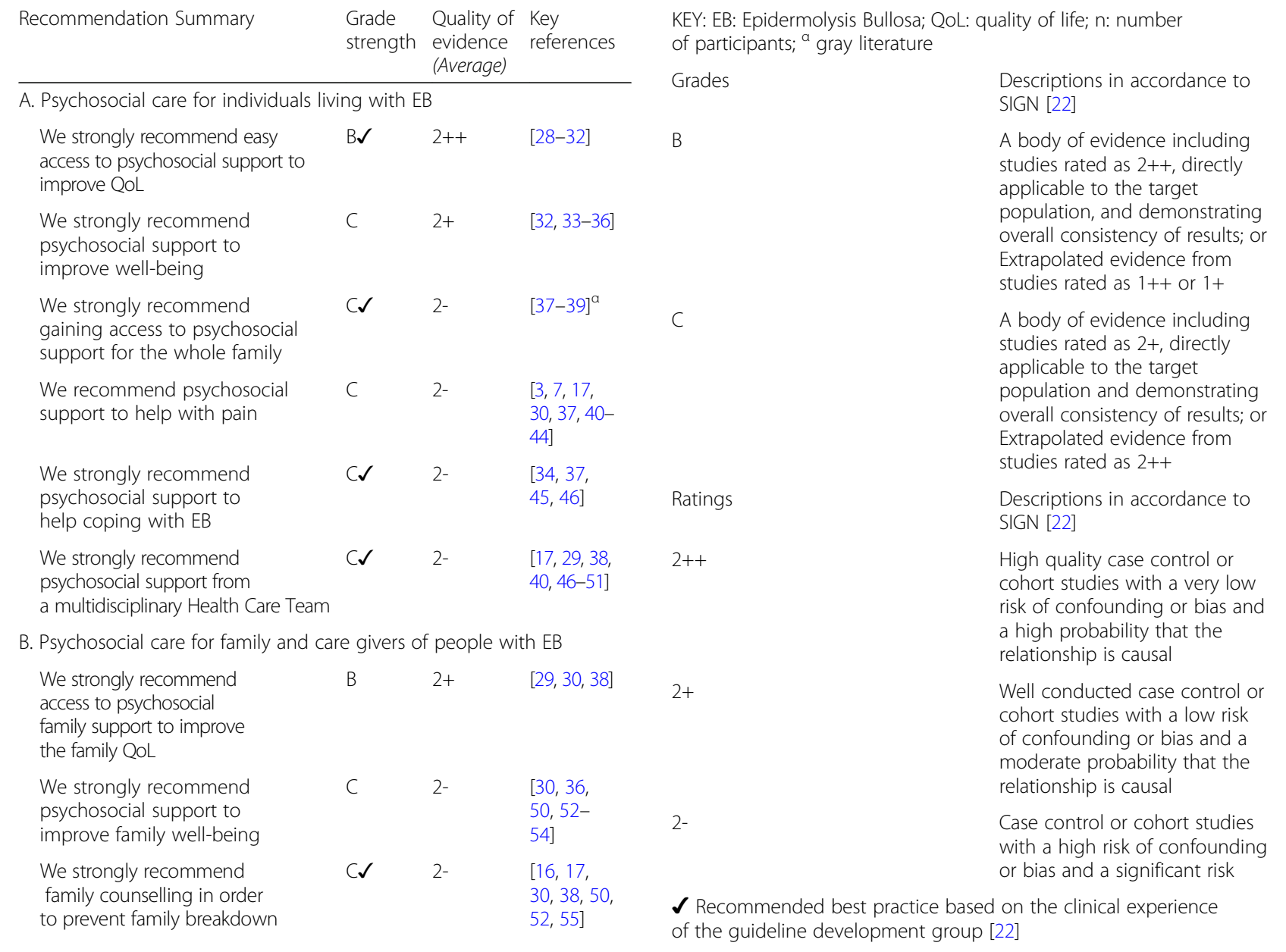

Recommendations (Continued)

\begin{tabular}{|c|c|c|c|}
\hline Recommendation Summary & $\begin{array}{l}\text { Grade } \\
\text { strength }\end{array}$ & $\begin{array}{l}\text { Quality of } \\
\text { evidence } \\
\text { (Average) }\end{array}$ & $\begin{array}{l}\text { Key } \\
\text { references }\end{array}$ \\
\hline $\begin{array}{l}\text { We strongly recommend } \\
\text { psychosocial support to } \\
\text { help the whole family to } \\
\text { cope with living with EB }\end{array}$ & C & $2-$ & $\begin{array}{l}{[16,17} \\
30,51]\end{array}$ \\
\hline $\begin{array}{l}\text { We recommend } \\
\text { psychosocial support to } \\
\text { reduce emotional burden } \\
\text { during daily painful procedures }\end{array}$ & C & $2-$ & $\begin{array}{l}{[35,37,} \\
45,46]\end{array}$ \\
\hline $\begin{array}{l}\text { We strongly recommend } \\
\text { easy access to a } \\
\text { multidisciplinary expert } \\
\text { team for the whole family }\end{array}$ & C & $2-$ & $\begin{array}{l}{[17,29} \\
39,50,51]\end{array}$ \\
\hline \multicolumn{4}{|c|}{ C. Self-care for professionals working with those affected by EB } \\
\hline $\begin{array}{l}\text { We strongly recommend } \\
\text { psychosocial expertise to help } \\
\text { people to cope with living with EB }\end{array}$ & C & $2-$ & {$[17,34,46]$} \\
\hline $\begin{array}{l}\text { We strongly recommend } \\
\text { a collaborative patient- } \\
\text { professional relationship }\end{array}$ & C & $2-$ & {$[40,49,56]$} \\
\hline We strongly recommend & C & $2-$ & {$[40,49,56$} \\
\hline
\end{tabular}

We strongly recommend offering support for
professionals working in EB

KEY: EB: Epidermolysis Bullosa; QoL: quality of life; n: number of participants; ${ }^{a}$ gray literature

$$
\begin{aligned}
& \text { SIGN [22] } \\
& \text { A body of evidence including } \\
& \text { studies rated as } 2++ \text {, directly } \\
& \text { applicable to the target } \\
& \text { population, and demonstrating } \\
& \text { overall consistency of results; or } \\
& \text { Extrapolated evidence from } \\
& \text { studies rated as 1++ or 1+ } \\
& \text { A body of evidence including } \\
& \text { studies rated as 2+, directly } \\
& \text { applicable to the target } \\
& \text { population and demonstrating } \\
& \text { overall consistency of results; or } \\
& \text { Extrapolated evidence from } \\
& \text { studies rated as } 2++ \\
& \text { Descriptions in accordance to } \\
& \text { SIGN [22] } \\
& \text { High quality case control or } \\
& \text { cohort studies with a very low } \\
& \text { risk of confounding or bias and } \\
& \text { a high probability that the } \\
& \text { relationship is causal } \\
& \text { Well conducted case control or } \\
& \text { cohort studies with a low risk } \\
& \text { of confounding or bias and a } \\
& \text { moderate probability that the } \\
& \text { relationship is causal } \\
& \text { Case control or cohort studies } \\
& \text { with a high risk of confounding } \\
& \text { or bias and a signficant }
\end{aligned}
$$
of the guideline development group [22] 
Table 1 Recommendations summary for the Psychosocial care of individuals living with EB

\begin{tabular}{|c|c|c|c|c|c|}
\hline Recommendations & Population & $\begin{array}{l}\text { Grade } \\
\text { strength }\end{array}$ & $\begin{array}{l}\text { Quality of } \\
\text { evidence } \\
\text { (Average) }\end{array}$ & $\begin{array}{l}\text { Quality of } \\
\text { evidence }\end{array}$ & $\begin{array}{l}\text { Key } \\
\text { references }\end{array}$ \\
\hline
\end{tabular}

i. We strongly recommend easy access to psychosocial support to improve Quality of life (QoL)

A multidisciplinary approach in treating EB improves

QoL for individuals with EB

- Psychological support and close monitoring of EB improves QoL.

- They facilitate participation in social activities.

- Patients with all types of EB including EBS report a great impairment in QoL due to restrictions in physical and social activities.

ii. We strongly recommend psychosocial support to improve well-being

To promote self-efficacy and support around body image to aid psychological well-being

- Having access to knowledge and resources about EB can help people have a greater role in managing their EB. This self-management

can help improve well-being.

- Improved self-efficacy and locus of control, as well as support around body-image could help to develop a more positive sense of well-being.

For support during transition periods in life (school transitions, transition into adulthood)

- Communication and education about EB

to improve people's understanding.

- Support from families, EB healthcare professionals and DEBRA.

iii. We strongly recommend gaining access to psychosocial support for the whole family

People diagnosed with EB should be referred for psychosocial support as early as possible in childhood or in adulthood, if the person with EB wishes

- To support the family unit.

Encourage supportive network for the family,

for example:

- Education about EB for others

- Provide access to DEBRA (or other

EB support groups)

iv. We recommend psychosocial support to help with pain

Pain is present for most children and adults with EB (all types) with profound psychosocial impact:

- Activity related pain can significantly affect psychosocial well-being and QoL (e.g. fear of/actual pain restricting social activities, affecting relationships with family and friends).

- Treatment related pain can make managing EB harder and link to procedural anxiety.

Adequate holistic pain management is essential as a focus for helping people with EB:

- Following pain guidelines.

- Offering approaches to help people with EB cope emotionally.

- Help with managing the impact of pain and the interlinked cycle of pain and psychosocial challenges.

v. We strongly recommend psychosocial support to help cope with living with $E B$

People with EB need support to cope with EB, and their ways of coping need to be supported by

Adults, children ( $n=12 / 185)$ EBS;

JEB; DDEB; RDEB; KS

Unclear if adults, children or both $(n=43 / 134)$ EBS; JEB; DDEB; RDEB;

Adults, children ( $n=120 / 248) \mathrm{EBS}$;

JEB; DDEB; RDEB

Review of inherited \& autoimmune

blistering diseases

Review of inherited \&autoimmune

blistering diseases

Adults $(n=87)$ RDEB, DEB, EBS

Children 10-14 years old $(n=11)$ EBS

(autosomal recessive)

Young male adults (aged 21-35 years)

with $\operatorname{RDEB}(n=5)$ and $\operatorname{EBS}(n=2)$

Observational report

$\checkmark$

Children ( $n=11 / 82)$ EBS; JEB; DDEB; RDEB

Children $(n=16)$ JEB Adult $(n=1)$ RDEB
B

$$
2++
$$

$1-$

$2+$

$2+$

$2-$

$1-$

[30]

$[31]$

[28]
C

$\begin{array}{cl}2+ & 1- \\ & 2+ \\ 2+ \\ 4 \\ & 4\end{array}$

$[29]$
$[30]$
$[31]$
$[28]$
$[32]$ 
Table 1 Recommendations summary for the Psychosocial care of individuals living with EB (Continued)

\begin{tabular}{|c|c|c|c|c|c|}
\hline Recommendations & Population & $\begin{array}{l}\text { Grade } \\
\text { strength }\end{array}$ & $\begin{array}{l}\text { Quality of } \\
\text { evidence } \\
\text { (Average) }\end{array}$ & $\begin{array}{l}\text { Quality of } \\
\text { evidence }\end{array}$ & $\begin{array}{l}\text { Key } \\
\text { references }\end{array}$ \\
\hline $\begin{array}{l}\text { others: participation in social life needs to be } \\
\text { supported } \\
\text { - Such as at school, the community, friendships, } \\
\text { employment. } \\
\text { - Aid access to supportive networks. } \\
\text { - Public education campaigns to help those } \\
\text { around them to understand EB and their needs. } \\
\text { Promote a sense of self-management of their EB } \\
\text { - This can help bring a sense of control over } \\
\text { certain aspects of the disease/treatment and pain. } \\
\text { Build social skills and communication } \\
\text { - Help in learning how to communicate about } \\
\text { EB to others and within the family unit. }\end{array}$ & $\begin{array}{l}\text { Children } 10-14 \text { years old }(n=11) \text { EBS } \\
\text { (autosomal recessive) } \\
\text { Children }(n=11 / 82) \\
\text { EBS; JEB; DDEB; RDEB } \\
\text { Children ( } n=24) \\
\text { EBS; JEB; DDEB; RDEB }\end{array}$ & & & $\begin{array}{l}2- \\
2-\end{array}$ & $\begin{array}{l}{[37]} \\
{[46]}\end{array}$ \\
\hline \multicolumn{6}{|l|}{$\begin{array}{l}\text { vi. We strongly recommend psychosocial support } \\
\text { from a multidisciplinary Health Care Team }\end{array}$} \\
\hline $\begin{array}{l}\text { Encourage access to, and a collaborative 'working } \\
\text { together' relationship with, an expert } \\
\text { multi-disciplinary team of professionals. } \\
\text { - Facilitate access to multidisciplinary professional } \\
\text { support for medical and psychosocial care across } \\
\text { the lifespan. } \\
\text { - At both specialist centres and community services }\end{array}$ & $\begin{array}{l}\checkmark \\
\text { Adults, children }(n=15) \text { RDEB } \\
\text { Children }(n=21) \text { EBS; JEB; DDEB; RDEB } \\
\text { Children }(n=11 / 82) \text { EBS; JEB; DDEB; RDEB } \\
\text { HCPs ( } n=33) 30 \text { stakeholders (HCPS, and } \\
9 \text { with EB RDEB, DDEB, EBS) } \\
\text { Adults ( } n=6) \text { JEB, DDEB } \\
\text { Children and Adults }(n=20) \text { EBS, JEB, DEB } \\
\text { Children }(n=16) \text { JEB } \\
\text { Children }(n=20) \text { EBS, JEB, RDEB }\end{array}$ & C & $2-$ & $\begin{array}{l}1- \\
2+ \\
2+ \\
2+ \\
2- \\
2- \\
2- \\
2- \\
2- \\
2+\end{array}$ & $\begin{array}{l}{[29]} \\
{[48]} \\
{[51]} \\
{[17]} \\
{[46]} \\
{[49]} \\
{[40]} \\
{[38]} \\
{[48]} \\
{[47]}\end{array}$ \\
\hline
\end{tabular}

Key: EB: Epidermolysis Bullosa; RDEB: Recessive Dystrophic Epidermolysis Bullosa; JEB: Junctional Epidermolysis Bullosa; DDEB: Dominant Dystrophic Epidermolysis Bullosa; EBS: Epidermolysis Bullosa Simplex EBS-I: Localised form of EBS; KS Kindler Syndrome; QoL: quality of life; n: number of; a: gray literature; $\Rightarrow$ this is an EB guideline

Grades

B

C

Ratings Descriptions in accordance to SIGN [22]

$1-$

$2++$

$2+$

$2-$

3

4

\section{Descriptions in accordance to SIGN [22]}

A body of evidence including studies rated as $2++$, directly applicable to the target population, and demonstrating overall consistency of results; or Extrapolated evidence from studies rated as $1++$ or $1+$

A body of evidence including studies rated as $2+$, directly applicable to the target population and demonstrating overall consistency of results; or Extrapolated evidence from studies rated as $2++$

Meta-analyses, systematic reviews, or RCTs with a high risk of bias

High quality case control or cohort studies with a very low risk of confounding or bias and a high probability that the relationship is causal

Well conducted case control or cohort studies with a low risk of confounding or bias and a moderate probability that the relationship is causal

Case control or cohort studies with a high risk of confounding or bias and a significant risk

Non-analytic studies, e.g. case reports, case series

\section{Expert opinion}

$\checkmark$ Recommended best practice based on the clinical experience of the guideline development group [22] 
Table 2 Recommendations summary for the Psychosocial care of Family and caregivers of people living with EB

\begin{tabular}{lll}
\hline Recommendations & Population & $\begin{array}{l}\text { Grade } \\
\text { strength }\end{array}$ \\
$\begin{array}{l}\text { Quality of } \\
\text { evidence } \\
\text { (Average) }\end{array}$ & $\begin{array}{l}\text { Quality of Key } \\
\text { evidence references }\end{array}$
\end{tabular}

i. We strongly recommend access to psychosocial family support to improve the family QoL

Early psychosocial support to improve QoL of the family unit for all subtypes EB and children with high infantile mortality:

- As caregivers QoL may also be impacted.

- Psychological support and close monitoring helps.

- Support is essential for family of palliative patients with EB.
Adults, children; 11 studies EBS; JEB; DDEB; RDEB Adults, children $(n=125 / 185)$ EBS; JEB; DDEB; RDEB; KS Children $(n=16)$ JEB ii. We strongly recommend psychosocial support to improve the family well-being
Support for the family to reduce emotional burden of caring for someone with

$\mathrm{EB}$ and improve well-being for the family unit:

Adults, children $(n=15)$ RDEB

Children, Adults

$(n=374 / 425)$

EBS; JEB; DDEB; RDEB

Home nursing can provide much needed relief and support

for primary caregivers and could reduce the need for hospital admission.

- Actively assist in seeking counselling before the family unit

is irreparably destroyed.

- Provide information about the nature, course and outcome of EB.

- Provide training in the management of patient symptoms.

- Access to Social media and face to face EB support groups might be beneficial for families.

Promoting family well-being can help the family enhance their strong and positive influence for those living with $E B$

- The way the family reacts to EB can be psychologically

assimilated by the person with EB, particularly children.

- Acceptance of the EB by the family is important and can

make it more bearable for the patient.

iii. We strongly recommend family counselling in order to prevent family breakdown

To help prevent the family unit breakdown, for the family of all EB subtypes:

- Strengthen family relationships.

To prevent family emotional breakdown or distress

- Support in managing life with EB.

To prevent parents' emotional breakdown or distress

- Specially provide support for single parents with a child

living with $E B$. adults) RDEB, EBS
Children, Adults

$(n=374 / 425)$

EBS; JEB; DDEB; RDEB

Adults, children

$(n=15)$ RDEB

Children $(n=11 / 82)$

EBS; JEB; DDEB; RDEB

Adults, children $(n=28 / 42)$

EBS; JEB; DDEB; RDEB

Children $(n=16)$ JEB

Children, Young Adults;

$(n=63 / 138)$ EBS; DDEB; RDEB+

EBS; JEB; DDEB; RDEB; KS
Adults, children $(n=125 / 185)$
B

$2+$

$1-$

$2+$

$2-$

[30]

[38]
C 2-

iv. We strongly recommend psychosocial support to help the whole family to cope with living with EB

Specialist home based psychosocial support for the family of all EB subtypes can help promote strategies to cope:

- Help access counselling to promote the intra-family

communication.

- Access help to manage EB and economic burden.

- Promote good relationships between the family

- Provide a home care program for respite, or support handing over physical care to others.
Children $(n=21)$

EBS; JEB; DDEB; RDEB

Adults, children $(n=125 / 185)$

EBS; JEB; DDEB; RDEB; KS

Adults, children $(n=28 / 42)$

EBS; JEB; DDEB; RDEB

Children $(n=11 / 82)$

EBS; JEB; DDEB; RDEB

v. We recommend psychosocial support to reduce emotional burden during daily painful procedures

Psychosocial support needs for parents and family to reduce the emotional burden of caring for someone living with $E B$ who has severe pain:

- Offer psychological support for caregivers. Parents/care givers can struggle with 'causing pain' due to dressing changes and wanting to protect their child from pain. This is very difficult emotionally for parents.

- Pain can negatively affect relationships within the family $\checkmark$

Children $(n=11 / 82)$

EBS; JEB; DDEB; RDEB

Adults, children; $(n=57)$ EBS-I

Adult $(n=6 / 20)$ JEB, DDEB
C

2

2-

[16]

$2-$

$C$

$2-$

$2-$ 
Table 2 Recommendations summary for the Psychosocial care of Family and caregivers of people living with EB (Continued)

\begin{tabular}{|c|c|c|c|c|c|}
\hline Recommendations & Population & $\begin{array}{l}\text { Grade } \\
\text { strength }\end{array}$ & $\begin{array}{l}\text { Quality of } \\
\text { evidence } \\
\text { (Average) }\end{array}$ & $\begin{array}{l}\text { Quality of } \\
\text { evidence }\end{array}$ & $\begin{array}{l}\text { Key } \\
\text { references }\end{array}$ \\
\hline \multicolumn{6}{|l|}{$\begin{array}{l}\text { and with friends. Help optimise pain management } \\
\text { techniques. } \\
\text { - Parents/carers can find it difficult to see people in severe } \\
\text { pain. Aid access to respite, independent carers and promote } \\
\text { independence with dressings. }\end{array}$} \\
\hline \multicolumn{6}{|c|}{ vi. We strongly recommend easy access to a multidisciplinary expert team for the whole family } \\
\hline $\begin{array}{l}\text { Provide access to recognised expert support and training for } \\
\text { the whole family } \\
\text { - Provide appropriate treatment and training or refer to } \\
\text { national EB experts. } \\
\text { - Referring to with the DEBRA or EB support network may } \\
\text { help. }\end{array}$ & $\begin{array}{l}\text { Adults, children; } 11 \text { studies } \\
\text { EBS; JEB; DDEB; RDEB } \\
\text { Adults, children }(n=15) \text { RDEB } \\
\text { Children }(n=21) \\
\text { EBS; JEB; DDEB; RDEB } \\
\text { Children ( }(n=11 / 82) \\
\text { EBS; JEB; DDEB; RDEB } \\
\text { Adult }(n=1) \text { RDEB }\end{array}$ & C & 2- & $\begin{array}{l}1- \\
2+ \\
2+ \\
2+ \\
4\end{array}$ & $\begin{array}{l}{[29]} \\
{[50]} \\
{[51]} \\
{[17]} \\
{[39]^{\alpha}}\end{array}$ \\
\hline \multicolumn{6}{|c|}{$\begin{array}{l}\text { Key: EB: Epidermolysis Bullosa; RDEB: Recessive Dystrophic Epidermolysis Bullosa; JEB: Junctional Epidermolysis Bullosa; DDEB: Dominant Dystrophic } \\
\text { Epidermolysis Bullosa; EBS: Epidermolysis Bullosa Simplex EBS-I: Localised form of EBS; KS Kindler Syndrome; QoL: quality of life; } n \text { : number of; a: } \\
\text { gray literature; } \Rightarrow \text { this is an EB guideline }\end{array}$} \\
\hline Grades & \multicolumn{5}{|c|}{ Descriptions in accordance to SIGN [22] } \\
\hline B & \multicolumn{5}{|c|}{$\begin{array}{l}\text { A body of evidence including studies rated as } 2++ \text {, directly applicable to } \\
\text { the target population, and demonstrating overall consistency of results; } \\
\text { or Extrapolated evidence from studies rated as } 1++ \text { or } 1+\end{array}$} \\
\hline C & \multicolumn{5}{|c|}{$\begin{array}{l}\text { A body of evidence including studies rated as } 2+\text {, directly applicable to the } \\
\text { target population and demonstrating overall consistency of results; or } \\
\text { Extrapolated evidence from studies rated as } 2++\end{array}$} \\
\hline \multicolumn{6}{|l|}{ Ratings Descriptions in accordance to SIGN [22] } \\
\hline $1-$ & \multicolumn{5}{|c|}{ Meta-analyses, systematic reviews, or RCTs with a high risk of bias } \\
\hline $2+$ & \multicolumn{5}{|c|}{$\begin{array}{l}\text { Well conducted case control or cohort studies with a low risk of confounding } \\
\text { or bias and a moderate probability that the relationship is causal }\end{array}$} \\
\hline $2-$ & \multicolumn{5}{|c|}{$\begin{array}{l}\text { Case control or cohort studies with a high risk of confounding or bias and a } \\
\text { significant risk }\end{array}$} \\
\hline 4- & \multicolumn{5}{|l|}{ Expert opinion } \\
\hline \multicolumn{6}{|c|}{$\checkmark$ Recommended best practice based on the clinical experience of the guideline development group [22] } \\
\hline
\end{tabular}

\section{A. Discussion of psychosocial care for individuals living with EB}

Quality of life (Grade: B) $\checkmark$

Two observational studies investigated the impact of EB on QoL in adults and children with all types of EB [28, 30]. They affirm that EB can have a severe impact on QoL with the physical symptoms of EB (such as itching, pain and stinging) having the highest impact on QoL for adults, along with restrictions to social activities and embarrassment due to their skin [28, 30]. Children identified embarrassment as the highest impacting factor, followed by physical symptoms and restrictions to play and activities. People with EBS particularly identified how pain restricted social activities [42].

Further work needs to be established regarding facilitating people with EB to participate in social activities, to enable greater QoL and well-being Although no interventions are investigated in the research, recommendations are that the provision of psychological support and the measurement and monitoring of QoL could be beneficial for people with EB [30, 32, 57] (Table 1i.).

\section{Wellbeing (Grade: $C$ )}

People with EB can have a negative body image due to the visibility of the condition and recognition of being different from others [33-34]. A negative body image can be related to poorer psychological well-being. Women and younger people with EB may struggle more than men in this respect [33]. For some the visibility of $E B$, such as on hands and face, can invite scrutiny from others $[34,37,46]$ as can the invisibility of EB for others [37]. The social impact of EB due to visible difference or exclusion from activities was most strongly identified in children's accounts of living with EB [34]. 
Table 3 Psychosocial management recommendations for professional working with EB

\begin{tabular}{|c|c|c|c|c|c|}
\hline Recommendations & Population & $\begin{array}{l}\text { Grade } \\
\text { strength }\end{array}$ & $\begin{array}{l}\text { Quality of } \\
\text { evidence } \\
\text { (Average) }\end{array}$ & $\begin{array}{l}\text { Quality of } \\
\text { evidence }\end{array}$ & $\begin{array}{l}\text { Key } \\
\text { references }\end{array}$ \\
\hline \multicolumn{6}{|c|}{ i. We strongly recommend psychosocial expertise to help people to cope with living with EB } \\
\hline $\begin{array}{l}\text { Access to EB specialised care } \\
\text { - Nurturing a good relationship between professionals, family } \\
\text { and person with EB } \\
\text { - Training for non-EB professionals }\end{array}$ & $\begin{array}{l}\text { Children } 10-14 \text { years old } \\
(n=11) \\
\text { EBS (autosomal } \\
\text { recessive) } \\
\text { Children ( } n=11 / 82) \\
\text { EBS; JEB; DDEB; RDEB } \\
\text { Children ( } n=24) \\
\text { EBS; JEB; DDEB; RDEB }\end{array}$ & C & $2-$ & $\begin{array}{l}2+ \\
2- \\
2-\end{array}$ & $\begin{array}{l}{[34]} \\
{[17]} \\
{[46]}\end{array}$ \\
\hline \multicolumn{6}{|c|}{ ii. We strongly recommend a collaborative patient-professional relationship } \\
\hline $\begin{array}{l}\text { - Training for professionals in working collaboratively } \\
\text { with patients. }\end{array}$ & $\mathrm{HCPs}(N=33)$ & C & $2-$ & $2-$ & {$[56]$} \\
\hline \multicolumn{6}{|c|}{ iii. We strongly recommend offering support for professionals working in EB } \\
\hline $\begin{array}{l}\text { - To promote well-being for the healthcare professional } \\
\text { - Emotional support is necessary: Personal support but also } \\
\text { on an organisational level. } \\
\text { - Importance of Professionals self-care: awareness, support } \\
\text { to do this and access to clinical supervision. } \\
\text { - Important to not work in isolation: the need to link in } \\
\text { with an MDT and to feel equipped through information } \\
\text { and education to help with psychosocial needs. }\end{array}$ & $\begin{array}{l}\text { Key Stakeholders } \\
(N=30) \\
\text { Key Stakeholders } \\
(N=30) \\
\text { Adults }(N=6) \text { JEB, DDEB }\end{array}$ & C & $2-$ & $\begin{array}{l}2- \\
2- \\
2-\end{array}$ & $\begin{array}{l}{[56]} \\
{[49]} \\
{[40]}\end{array}$ \\
\hline \multicolumn{6}{|c|}{$\begin{array}{l}\text { Key: EB: Epidermolysis Bullosa; RDEB: Recessive Dystrophic Epidermolysis Bullosa; JEB: Junctional Epidermolysis Bullosa; DDEB: Dominant Dystrophic } \\
\text { Epidermolysis Bullosa; EBS: Epidermolysis Bullosa Simplex EBS-I: Localised form of EBS; KS Kindler Syndrome; HCPs: Health care professionals; MDT: } \\
\text { multidisciplinary team; n: number of; }{ }^{\text {a: }} \text { gray literature; } \Rightarrow \text { this is an EB guideline }\end{array}$} \\
\hline Grades & \multicolumn{5}{|c|}{ Descriptions in accordance to SIGN [22] } \\
\hline C & \multicolumn{5}{|c|}{$\begin{array}{l}\text { A body of evidence including studies rated as } 2+\text {, directly applicable to the target } \\
\text { population and demonstrating overall consistency of results; or Extrapolated } \\
\text { evidence from studies rated as } 2++\end{array}$} \\
\hline Ratings & \multicolumn{5}{|c|}{ Descriptions in accordance to SIGN [22] } \\
\hline $2-$ & \multicolumn{5}{|c|}{$\begin{array}{l}\text { Case control or cohort studies with a high risk of confounding or bias and a } \\
\text { significant risk }\end{array}$} \\
\hline
\end{tabular}

Although there were no intervention-based studies within the literature, the authors recommend that interventions are needed to enable people with $\mathrm{EB}$ to have a stronger belief in being able to gain control over aspects of their condition. This can be associated with well-being and improved body image, particularly in children with EB [33]. Having access to knowledge and resources about $\mathrm{EB}$ and inviting people with $\mathrm{EB}$ to take a collaborative rather than 'being done to' approach to their care, can help them to have a greater role in managing their EB. Specific support to help with body image is also advocated.

Transition periods of life were identified as potentially stressful for people with EB, impacting on their well-being and coping. Examples of transitions include changing classes at school and having to inform others about EB [34]. Although there is a lack of research into adults' experiences, expert opinion and experienced clinicians identify that transitions in adulthood can also give rise to additional stress, such as transitioning from school to university/college or the work place and when developing new relationships. Children with EB and their families can have anxieties around transitioning from paediatric to adult healthcare settings, and regarding building relationships and trust within a new healthcare environment [58]. Transition should be seen as a process, not a single event, and partnership working between the clinical staff in both health settings, community services and family are essential in facilitating a smooth transition [58]. The provision of education, information and support for the individual and their family, from EB professionals, is recommended to help improve psychological well-being during these transition periods [34, 36, 58] (Table 1.ii.).

\section{Family (Grade: C) $\checkmark$}

There is limited research on the interaction between the impact of EB on the family unit and the person living 
with EB, and none looking at this into adulthood. The impact of EB on the family unit can, however, be profound and recommendations regarding the family's psychosocial needs are covered below. Based on clinical experience and the expertise in the panel, it is likely that the nature of EB will impact on early attachment relationships and bonding within the family unit. The need for psychosocial support for the person with EB as part of a family unit is therefore advocated for all types of EB diagnosis [37] (Table 1.iii.). People with EB can struggle with a sense of difference compared to others in their family, and their family life may be different to that of other families. Empowering those around the individual to understand EB may help. Having access to peer relationships with other families and people living with EB may help provide a sense of being understood, alongside education being available to those around the person with EB and their family; though not all individuals or families may wish to access this resource [38, 39]. DEBRA events and online social media support networks could also be beneficial $[35,36]$.

\section{Pain (grade: $\mathrm{C}$ )}

The strongest conclusion to be drawn from this review is that pain is a key theme for many people affected by EB. The limited literature indicates that pain can have a negative effect on children and adult's QoL and psychosocial well-being [59]. Most people with EB have pain due to their skin wounds and other extracutaneous symptoms. This can be severe and unrelenting, with aspects of treatment often being linked to painful procedures. The pain itself can have profound effects, being associated with frustration, embarrassment, anxiety, sadness and, especially for children, fear [3, 14, 37, 40, 42]. Pain impacts on friendships and family relationships. Activity related pain can restrict many areas associated with positive psychosocial well-being and coping; such as social participation, having access to peer relationships, occupation, meaningful activities, and maintaining friendships $[3,37,40] .{ }^{\Rightarrow}$ It is therefore important that support is given to manage not just the pain itself, but also its impact psychologically and socially, and that all possible is done to manage pain in accordance with pain management guidelines [7].

There is much within general non-EB specific literature on psychosocial techniques for managing pain. There are reviews regarding interventions for paediatric pain $[60,61]$, other sources $[62,63]$ and the ${ }^{\Rightarrow}$ British Pain Society Guidelines for pain management programmes for adults which may be helpful resources [64].

These psychosocial aspects to pain management could be applicable to the EB population but no intervention studies explore this generalizability. Indeed, people with EB describe coping with pain by "blocking it out" or distraction $[40,42]$ and some studies suggest a limited use of techniques such as deep breathing and relaxation by people with EB [40]. We recommend that pain management is a priority within clinical management and research aimed at improving the psychosocial well-being of people with EB (Table 1.iv.).

\section{Coping (Grade: $C) \checkmark$}

People with EB develop individualised ways of coping with the condition. Themes within the literature associated with coping include having a sense of self-management, therefore control, over aspects of their condition and treatment; particularly for children with EB [37]. This is echoed in the recommendation for a collaborative approach to healthcare outlined below.

Wherever possible support and help to participate as fully as possible in social life needs to be advocated. This includes at school, within the community and, as an adult, within opportunities for employment and a role within society. Whilst there is an ongoing struggle and need to achieve a balance between activity and risk of skin damage for many people with EB, access to social participation is highlighted by both adults and children with $E B$ as important parts of their coping with the condition [32, 34, 45]. Such activity also allows access to other forms of coping such as friendships and support networks. In childhood this socialisation and mastery of activities is important in meeting developmental milestones and psychosocial development.

One of the barriers to participation in activities and social roles can be a perceived or actual lack of understanding of others regarding the needs of people with EB. Support and education in this regard can help, such as public campaigns and, more specifically, support within schools and for employers to understand how they can assist [34]. Communication within the family unit, alongside confidence in communicating about EB to others is important, particularly in childhood for building social confidence $[37,45,46]$ (Table 1.v.).

\section{Access to professional healthcare (Grade: $C$ ) $\checkmark$}

Multiple studies suggest that being able to access a MDT of professionals, providing treatment and advice on the medical and psychosocial aspects of EB across the lifespan, is key for improving psychosocial well-being, coping and QoL for people with EB [38, 40, 47-50]. Having a team of people who can work collaboratively with the person with $\mathrm{EB}$ and, especially in the case of children with EB, their family and carers, can help provide a sense of support and ease the burden of EB in everyday life $[29,37,50,51]$. This is also echoed in the other recommendations around education and advice to improving self-management of EB to aid a sense of self-efficacy and control over the condition. Having 
professionals who are trained in recognising, understanding and helping with psychosocial issues is paramount and may also help in forming a supportive collaborative relationship [47, 49,56] (Table 1.vi.).

\section{B. Discussion of psychosocial care for family and care givers of people living with EB}

\section{Quality of life (grade: B) $\checkmark$}

Life with EB has a significant impact on the entire family and can lead to an impairment in the QoL for both the child and parents $[17,29,46,52,53,56]$. The main determinants associated with QoL for the family of a child with EB are [1] the severity, extent, unpredictable course and (in) visibility of the disease [2], the pain and poor QoL of the child [3], restrictions in employment and leisure time [4], never being off duty and [5] ignorance and lack of skills of care providers [17, 29, 30, 52, 51]. Findings show early psychosocial assessment and monitoring can improve QoL of the entire family of children with EB, regardless of which sub-type and the expected life span $[17,29,30,38]$ (Table 2 .i.).

\section{Well-being (grade: C)}

Many studies have identified the impact of EB on the physical and emotional well-being of parents and caregivers. This includes difficulties in organizing care, problems within their own relationship, having less energy, the unpredictability of the disease and associated difficulties with planning, both in the short and long-term. These problems can affect the whole family, impacting on each member's ability to achieve their desires and significantly lowering their level of life satisfaction $[17,51,65]$ (Table 2. ii.).

Several studies emphasise the importance of early, extensive and long-term support for parents or caregivers which could involve [1]: home nursing to provide relief and help for primary caregivers and could reduce the need for hospital admission [2], provision of information on the nature, course and outcome of the patient's disease [3], training of relatives in the management of patient symptoms and in the reinforcement of relatives' social networks [4], and the use of social media [30, 36, 50, 52]. (Table 2. ii.). A study further explores how online communities could be a particularly helpful way for people with EB to share experiences and gain social support in a manageable way across the world [64].

The reaction of family members to the condition seems to be psychologically assimilated by their children and can impact on them as adults living with EB. This shows that it is important to make parents aware of how their reaction to their child's illness affects the well-being of the whole family $[53,54]$ (Table 2. ii.).

\section{Breakdown of the family unit (grade: $\mathrm{C}$ )}

The potential impact of EB on the QoL and well-being of parents with children who have EB, increases the risk of a breakdown of the entire family unit. To prevent a family breakdown, several studies recommended helping families managing life with EB, strengthening family relationships and especially supporting single parents or female carers who may require more support $[16,17,30,38,50,52]$. It is particularly recommended that parents place importance on, and pay attention to, securing their own leisure time, holidays and social life to prevent a breakdown of the family unit [55] (Table 2. iii.).

\section{Access to healthcare providers and EB networks (C) $\checkmark$}

Access to health professionals and EB networks is recommended, where patients and caregivers can receive appropriate treatment, information and training regarding the day-to-day management of their $\mathrm{EB}$, and have the possibility to discuss personal experiences; for example at family weekends or workshops for parents and patients [17, 29, 39, 50, 51, 66, 67] (Table 2. vi.).

\section{Coping (grade: $\mathrm{C}$ )}

Parents experience great stress due to inadvertently inflicting pain on their child when managing their daily care. The challenge of 'switching' roles between being caregiver and parent can require increased efforts to cope, not only with physical tasks but also cognitive and emotional challenges [17, 51, 65, 68]. Support programs or a care manager should [1] encourage parents to establish a normal routine for the child and family [2] dedicate time for themselves and as a couple to help coping [3] create a support network with the spouse, extended family, medical staff and respite opportunities from care $[16,17,69]$ (Table 2. iv.).

\section{Pain (Grade: $C) \checkmark$}

Coping with pain is interlinked with living with EB from birth. Pain can result in negative effects on relationships within the family $[40,42]$. It is the primary concern for caregivers who helplessly observe the wounds on the child's body and worry about causing pain as a consequence of providing the care their child requires $[17,40,65]$. Often parents separate their emotions during painful tasks to cope [17]. Alternatively, they do not get involved in the daily dressing routines, which can have a positive impact on the family unit [40]. Formal expert assistances to support people living with EB to become more independent with dressings, as well as opportunity to access to outside carers, would support the family unit [40] (Table 2. v.). 


\section{Discussion of self-care for professionals working with those affected by EB}

It is important that people with EB have access to health

care professionals with appropriate expertise and

experience in EB (grade: $C$ )

Access to health care professionals within the hospital and community has been recommended, though most of the studies in this area focus on supporting children with EB [49] (Table 3. i). Professionals need to feel they have adequate expertise and training to manage the complexities of EB. There will naturally be limits to the resources available and it is important to identify when other services may be better placed to offer support. Increased awareness and education is needed to equip non-EB specialist community services to respond to the wide range of physical and psychosocial needs of individuals with EB and their caregivers. Online community platforms could form a helpful way to disseminate EB related factual information [64], though reliance on online and telehealth platforms may need to be avoided when physical medical examination by specialists forms a crucial part of EB medical care.

\section{Health care professionals need to aim for collaborative patient-professional relationships}

Studies have also made recommendations regarding the process of supporting adults with EB [14, 38, 40, 70]. Physicians need to acknowledge "the active role of the patients as an informed, involved and interactive partner in the treatment process" [70]. Professionals providing medical intervention need to support patients to develop confidence and motivation to use their own skills and knowledge, enabling them to take effective control over managing their condition. Adults with EB often view themselves as "experts yet also valuing the expertise of others" [40]. EB care needs to be viewed as "a partnership" between individuals with EB and healthcare professionals. Striking a balance between maintaining and valuing self-efficacy in managing EB, whilst promoting access to support and specialist intervention, is very important. Professionals providing these services would benefit from training in working with people with rare conditions. In particular, the process of supporting assertive and well informed patients, as well as patients who decline or struggle to engage with healthcare services (Table 3. ii).

\section{Healthcare professionals working with people with EB} should work in experienced teams providing support for themselves (Grade: C)

Clinicians working in the area also benefit from access to professional support [32]. EB professionals often work in isolation and this is not good for their own psychological health. Access to clinical supervision, skills training in recognising psychosocial difficulties and access to multidisciplinary team support are important considerations. This is an important recommendation to consider the deep emotional impact that HPCs can encounter when working in EB care [71]. A range of professional are involved in EB care at specialist hospital, community and voluntary settings; it is important that all involved have access to shared support and supervision. Issues around professional limitations, difficulties and boundaries need to be acknowledged and discussed openly rather than managed in isolation (Table 3 . iii).

\section{Conclusions}

These guidelines provide evidence-based recommendations to optimise the care for people living with EB and their families. EB is a disease that impacts on many different aspects of life. Besides the extensive medical aspects, psychosocial well-being is also highly affected. Many factors influence psychosocial well-being and create a complex interaction between disease-specific features, individual characteristics, environmental issues and socio-economic circumstances.

Starting from an evidence-driven approach, these guidelines form a framework with recommendations that can be used by people living with EB, their families and caregivers and professionals. After a comprehensive systematic literature search, the main conclusion we can make is that evidence from interventional studies is limited. Most existing research is explorative in focus, aiming to investigate the impact of EB, rather than interventions which help. Therefore, these guidelines provide general recommendations that can be used as a basis to start an individual-focused approach for supporting people with EB and their families, and to inform future research.

There is a good understanding of which parts of life are difficult for people with EB. The management of pain is a key part of psychosocial well-being, impacting on QoL and coping with EB [40]. Physical discomfort (pain, itching, wound care etc.) plays an important role in the limitations people with EB and their family are experiencing. To cope with this discomfort is a daily mission, demanding a great amount of effort and energy. Whilst there is a $\Rightarrow$ CPG specifically on pain in EB [7] this CPG utilised only research specifically on pain and psychosocial aspects for people with EB; the Pain specific CPG included non-EB specific papers. There is a lack of intervention studies exploring the application and efficacy of psychosocial techniques for managing pain in EB. Techniques such as pacing and planning activities, relaxation, distraction, managing anxiety, tension and cognitive attributions may all be helpful but there is no clear evidence allowing this formal recommendation. 
It seems that living with $\mathrm{EB}$ is more bearable when people with EB feel supported and integrated in society. Participation in social life, peer support and a sense of self-realisation are key constructs needed for people with EB to optimise their social well-being and to cope with the difficult effects of EB. In our expert opinion and synthesis of the existing, though limited, evidence base, multidisciplinary professionals, and those supporting and caring for people with EB, should use their expertise to help people living with $\mathrm{EB}$ and their families to realise these constructs. People with EB and their caregivers will become the experts in their own situation. A strong collaboration between the scientific driven expertise of professionals and the experience driven expertise of people with $\mathrm{EB}$ and their surroundings is recommended.

Starting from infancy, children with EB need to be encouraged to follow their psychosocial developmental milestones, alongside meeting their physical needs. More concretely, this could mean that in early childhood a supportive team should focus on pain management so there can be a secure attachment between children, their parents and the surrounding world. When they are older, they should be able to discover the world, being supported to have a certain grade of mobility and independence: psychologically, socially and where possible physically. As children grow into adulthood, there are a lot of obstacles disturbing their process of psychosocial development and management of EB. Examples of those possible obstacles are: gaining independency, pain as a strong conditioner to developing anticipatory anxiety and general anxiety, absence from school and peer relationships, physical limitations influencing the ability to participate in social activities, difficulties with poor body image, challenging transition periods and identity development. Young adults with EB could wrestle with difficult themes such as sexuality, intimacy, relationships and the sense of reaching their potential in life (self-realisation). Also, for adults with EB, it is not easy to find their way and place in society, but having a sense of belonging, a role, routine and meaningful activity all help with their psychosocial well-being.

The interaction of physical limitations and discomfort caused by EB, with these aforementioned psychosocial developmental tasks that every child and adult have to go through, is complex. There is a scarcity of research about which interventions in childhood give the best outcomes in adulthood, not only in EB, but also in other chronic and invasive diseases. There is also limited research into how adults living with $\mathrm{EB}$ and their families can overcome and manage the psychosocial challenges of EB. Most of the recommendations made in this paper are therefore not concrete and a golden standard of care could not be created.
A supportive network seems invaluable. The biggest recommendation we can make to optimise psychosocial well-being of those with EB and their families, is to facilitate participation in society and peer support. Every person has to find his role in life and society and the search for this can be really difficult for those living with EB. These challenges could also extend to family members caring for someone with EB where parents may have to adapt/change family roles to meet the care needs of a child with EB. This can have social and economic implications for the whole family and affect each member's ability to achieve their own desires.

Parents can experience immense psychological stress due to inflicting pain on their child while managing their daily care. The challenge of being both the parent who wants to protect their child and the caregiver who has to, at times, impose pain due to the child's physical and medical needs can take a toll on parent's well-being. Therefore, it is very important to provide early, extensive and long-term support for family members to enable them to cope with the emotional burden that they carry as care providers and regarding their option to bring in outside caregivers or respite. Psychosocial support is recommended to assist families to manage life with EB. Supporting families can help to strengthen family relationships, prevent family breakdown and improve family members QoL and well-being. The literature suggests a link between family members' reaction to $\mathrm{EB}$, which is assimilated by the child, impacting later on into adulthood. Therefore, if family members are supported, this can also have psychological benefits for the individual living with EB.

There can be a lack of knowledge and understanding about EB in schools, working places, leisure time groups or in peer relationships. Moreover, many social activities or public places are not sufficiently adapted for the needs of people with EB; like supermarkets, shops, restaurants, hotels, transportation. A focus on raising awareness of $\mathrm{EB}$ in general and on the psychosocial needs of people with EB is essential. Providing information and training about EB for family members is also recommended to enable them to have a deeper personal understanding about the condition and disease process. Providing family members with information also can equip them to feel more confident in managing situations where EB is not understood. The role of the $\mathrm{HCP}$ is important in assisting family members and carers in their understanding of EB and providing them with social support.

Health care professionals can play a supportive role in all of the aforementioned aspects of life and development. They should use their expertise to provide an individualised approach for every person with EB. This can be a demanding task and there are limits to 
resources available; being aware of the limits and boundaries to their professional responsibilities and capabilities is important. The complexity of this disease is also felt by health care professionals. Feelings of powerlessness and not being able to help enough can be overwhelming, especially given the potentially long-term relationship between professionals and persons living with EB and their family. Therefore, it is essential that health care professionals adopt self-care awareness. They have to take care of themselves in order to be able to care for others. Clinical supervision, having space to reflect and process their experiences of caring and being able to rely on colleagues in a MDT appears necessary. Otherwise the burden of EB can also be hard to carry for health care professionals.

\section{Limitations of the guideline}

The authors acknowledge limitations with this CPG. The panel is formed from international volunteers from the EB community. They are experts in EB but not on CPG methodology. The contribution of a methodology expert to the panel has, however, sought to ensure a high quality robust methodology process. As EB is a rare condition there is a limited numbers of volunteering experts, also people living with $\mathrm{EB}$ can be very unwell very quickly, and professional's clinical responsibilities take priority. This can all add some limitations and challenges but despite this all panel members were encouraged to participate in all stages of developing these recommendations; to promote ecological validity and ensure an inclusive approach.

The CPG focuses only on summarising the published papers and gray literature identified by the search process. This is presented within the context of the primary six outcomes and utilises only EB specific papers. There may well be an overlap regarding the psychosocial difficulties experienced by people with EB and their families, and other conditions or groups of people: such as, for example, people with other physical differences, rare diseases or life-long, painful or and fluctuating conditions. A next step may be to look at the literature in these areas to see if it can be generalised to EB populations. The EB community, in terms of people with $E B$, their families and professionals, is a small one. The individuals forming the review panel all chose to not be anonymous with their feedback. Whilst the authors' names were hidden from the review panel, it is likely that some may have known the people writing this review. The implication for the peer review process is unknown. This may be taken as a strength, allowing the writing panel to follow up any comments and points made directly, but it may be a limitation in that the

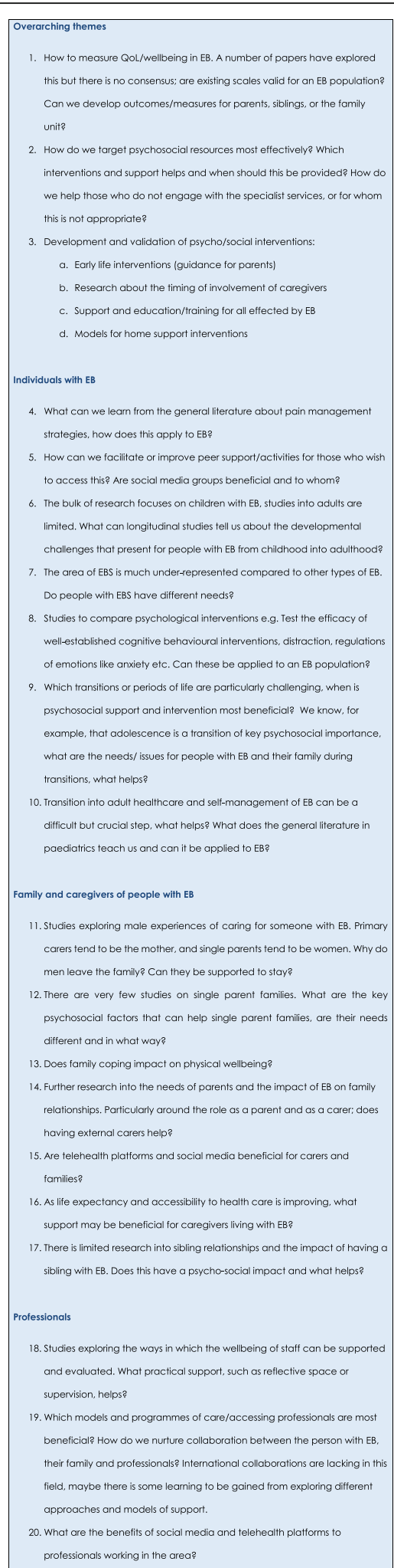

Fig. 6 Areas of research for the individual, family, caregivers and professionals 
review panel may not be seen as wholly 'independent' from the authors. With funding for clinical care being limited, with a keen focus on funding for research into physical care, the authors acknowledge that the review panel may carry their own biases regarding their interpretation of the guidelines, their support for its publication, or may be competitors with biases towards the centres involved in this guideline.

\section{Future research}

This guideline highlights the need for further high-quality research, to understand how best to support and manage the psychosocial needs and coping of people living with EB and their families. Present research goes some way towards understanding the nature of the psychosocial challenges presented by EB, but little is known about how to actually address or manage these effectively. Whilst there is evidence supporting psychosocial interventions for a range of difficulties commonly experienced by people with $\mathrm{EB}$, in areas such as pain management, anxiety and social interactions, there is limited research investigating the application of these to an EB population. There is a lack of focus on adulthood as opposed to managing EB in childhood, and EBS is also under-represented. Two areas of research paucity therefore include studies evidencing interventional approaches and on the management of psychosocial difficulties into adulthood. The rarity of EB may lead to difficulties with small and heterogeneous samples, making quantitative studies complex: international collaborations may be explored as an option to help.

The research questions and areas have emerged as requiring further investigation (Fig. 6):

\section{Implementation of guideline recommendations and update}

DEBRA International aims to ensure that the EB guidelines address the needs of patients internationally. These guidelines will be translated into other languages and patient versions will be made to aid accessibility.

These guidelines could be disseminated and promoted through education for professionals and considering how they could be incorporated into clinical practice. The guidelines were presented at the International DEBRA Congress 2018. The implementation and impact of these recommendations could be monitored and evaluated through audits, education programme registration, and the CPG Evaluation Form: Pre implementation (Additional file 3). The panel recommends sites to pre-audit practice, implement the CPG and re-audit to test improvement, audits tools can be used from SIGN. DEBRA International would value your feedback on the findings to continue to improve CPG quality.
The guidelines should be updated every $3-5$ years or if there is a significant breakthrough in EB psychosocial care from the publication date. We recommend a re-run of search terms to see if a full review is warranted at this point.

\section{Additional files}

Additional file 1: Author and Review Panel Membership. (PDF 422 kb)

Additional file 2: Copy of Appraisal and bias Tool. (PDF 638 kb)

Additional file 3 CPG Evaluation Form: Pre implementation. (PDF 138 kb)

\section{Abbreviations}

AGREE: Appraisal of Guidelines for Research \& Evaluation; AMED: Allied \& complementary medicine; APA: American Psychological Association; CASP: Critical Appraisal Skills Programme; CEO: Chief Executive Officer; Col: Conflict of interest; CPG: Clinical practice guideline; DDEB: Dominant Dystrophic Epidermolysis Bullosa; DEB: Dystrophic Epidermolysis Bullosa; DEBRA: Dystrophic Epidermolysis Bullosa Research Association; DI: DEBRA International; EB: Epidermolysis Bullosa; EB-CLINET: Epidermolysis Bullosa Clinical Network; EBS: Epidermolysis Bullosa Simplex; EBS-I: Localised form of Epidermolysis Bullosa Simplex; GRADE: Grading of Recommendations Assessment, Development and Evaluation; HCPs: Health Care Professionals; HMIC: Health Management Information Consortium; JEB: Junctional Epidermolysis Bullosa; KS: Kindlers Syndrome; MDT: Multi-disciplinary Team; NICE: National Institute for Health and Care Excellence; PhD: Doctor of Philosophy, an academic grade; PICOS: Participants, Interventions, Comparisons, Outcomes and Study Design; Prof: Professor; QoL: Quality of Life; RDEB: Recessive Dystrophic Epidermolysis Bullosa; SIGN: Scottish Intercollegiate Guidelines Network

\section{Acknowledgements}

We thank the working panel members for giving their time and sharing their knowledge and experiences. We would like to thank Estrella Guerrero Solana social worker from DEBRA Spain; Avril Kennan, PhD, CEO at Medical Research Charities Group, Ireland; the librarians at Heart of England NHS Foundation Trust and Cristina Has, Prof at University Medical Center Freiburg. We would like to thank our review panel for their contribution, please see Additional file 1 for details. Thanks also to University College London and EB-CLINET for access to meeting rooms.

\section{Funding}

The Heidi Ellingsen Silseth Fund was awarded by DEBRA Norway and approved by DEBRA International. The views or interests of the funding body have not influenced the final recommendations.

Availability of data and materials

Can be obtained from corresponding author as required.

\section{Disclaimer}

The recommendations contained in these guidelines do not indicate an exclusive course of action or serve as a standard medical care. Variations, taking individual circumstances into account, may be appropriate. The authors of these guidelines have made considerable efforts to ensure the information upon which they are based is accurate and up to date. Users of these guidelines are strongly recommended to confirm that the information contained within them. The authors, DEBRA Norway, or DI accept no responsibility for any inaccuracies, information perceived as misleading, or the success of any treatment regimen detailed in the guidelines.

\section{Authors' contributions}

KM, CPG chair, attended the first meeting; conducted literature searches; paper filtration and appraisal; outlined outcome summaries; lead and facilitated the recommendation meeting; was involved in the recommendation summary and drafted the manuscript; incorporated feedback from review panel and submitted the CPG. S G: CPG co-chair, attended the first meeting; outlines and conducted paper filtration and appraisal; outlined outcome summaries; lead and facilitated the 
recommendation meeting; was involved in the recommendation summary and drafted the manuscript; incorporated feedback from review panel and submitted the CPG. J KA CPG Patient representative, attended a patient focus group to inform the $C P G$, the first meeting; and the recommendation meeting; provided feedback on the manuscript. RBC, CPG Patient representative, linked virtually to the first meeting; conducted paper filtration and appraisal; outlined outcome summaries; attended recommendation meeting; was involved in the recommendation summary and was involved in drafting the manuscript; incorporated feedback from review panel. FB Member; conducted paper filtration and appraisal; outlined outcome summaries; attended recommendation meeting; was involved in the recommendation summary. AD Member; conducted literature searches; paper filtration and appraisal; outlined outcome summaries; attended recommendation meeting; was involved in the recommendation summary and was involved in drafting the manuscript; incorporated feedback from review panel. NGG Member; attended a patient focus group to inform the CPG, the first meeting; and the recommendation meeting; conducted literature searches; paper filtration and appraisal; outlined outcome summaries; was involved in the recommendation summary. G J, CPG Patient representative, linked virtually to the first and recommendation meetings; conducted paper filtration and appraisal; outlined outcome summaries; was involved in the recommendation summary; provided feedback on the manuscript. BK Member; helped facilitate the first meeting; and attended the recommendation meeting; conducted literature searches; paper filtration and appraisal; outlined outcome summaries; was involved in the recommendation summary and was involved in drafting the manuscript; incorporated feedback from review panel. PJM Member; attended a patient focus group to inform the CPG and took minutes, helped facilitate the first meeting; and attended the recommendation meeting; conducted literature searches; paper filtration and appraisal; outlined outcome summaries; was involved in the recommendation summary and was involved in drafting the manuscript; incorporated feedback from review panel. FP Member; conducted paper filtration and appraisal; outlined outcome summaries; linked virtually to the recommendation meeting; was involved in the recommendation summary and was involved in drafting the manuscript. $K$ $\mathrm{S}$ Member; facilitated room access and attended the first and recommendation meetings; conducted paper filtration and appraisal; outlined outcome summaries; was involved in the recommendation summary and gave feedback on manuscript. VZ, CPG Patient representative, attended the first and recommendation meetings; provided feedback on the manuscript. KMC Project manager and member; submitted application for CPG; was awarded funding; organised and facilitated the patient focus group to inform the CPG, organised and attended the first meeting, provided methodologist support, conducted literature searches; paper filtration and appraisal; outlined outcome summaries; managed database for articles and appraisal; attended the recommendation meeting; was involved in the recommendation summary and was involved in drafting the manuscript; and helped with CPG submission. All authors read and approved the final manuscript.

\section{Authors' information}

Additional file 1

Ethics approval and consent to participate

Not applicable.

\section{Consent for publication}

Not applicable.

\section{Competing interests}

Two authors declared potential Col with respect to this guideline: they were associates to DEBRA Norway and DI executive team; guideline Coordinator for $\mathrm{DI}$ and project manager of this CPG. These authors were therefore not involved in the final recommendation manuscript editions post review panel feedback. Two reviewers declared a Col; one reported to "hold to different operating frameworks and assumptions as well as professional competitors and rivals in a pool of diminishing mental health resources"; for the other, the guidelines directly relate to their work, PhD and research. The Col were reviewed by the Chairs and DI CPG coordinator and were considered not to influence the recommendations. No one involved in the guideline has any connection to manufacturers within the field of EB or medical pharmaceuticals. Please see Additional file 1.

\section{Publisher's Note}

Springer Nature remains neutral with regard to jurisdictional claims in published maps and institutional affiliations.

\section{Author details}

${ }^{1}$ University Hospitals Birmingham NHS Trust, Solihull Hospital, Solihull, B91

2JL, UK. ' Universital Hospitals Leuven, Leuven, Belgium. ${ }^{3}$ DEBRA Norge and person living with JEB, Stavanger, Norway. ${ }^{4}$ California State University, Fullerton, CA, USA. ${ }^{5}$ Our Lady's Children's Hospital Crumlin, Dublin, Ireland. ${ }^{6}$ Guy's and St Thomas' Hospitals NHS Foundation Trust, London, UK. ${ }^{7}$ DEBRA Spain, Marbella, Spain. ${ }^{8}$ Psychology graduate and person living with EBS, Liverpool, UK. ${ }^{9}$ The University Medical Center Groningen, Groningen, the Netherlands. ${ }^{10}$ DEBRA Chile, Santiago, Chile. ${ }^{11}$ Great Ormond Street Hospital NHS Foundation Trust, London, UK. ${ }^{12}$ DEBRA Croatia, Zagreb, Croatia.

${ }^{13}$ DEBRA International, Vienna, Austria.

Received: 11 December 2018 Accepted: 1 May 2019

\section{References}

1. DEBRA. What is Epidermolysis Bullosa? 2018. http://www.debra.org/ whatiseb. Accessed 20 Apr 2018.

2. Fine JD, Bruckner-Tuderman L, Eady RAJ, Bauer EA, Bauer JW, Has C, et al. Inherited epidermolysis bullosa: updated recommendations on diagnosis and classification. J Am Acad Dermatol. 2014;70:1103-26.

3. Fine JD, Johnson LB, Weiner M, Suchindran C. Assessment of mobility, activities and pain in different subtypes of epidermolysis bullosa. Clin Exp Dermatol. 2004;29:122-7.

4. Fine JD, Johnson LB, Weiner M, Suchindran C. Cause-specific risks of childhood death in inherited epidermolysis bullosa. J Pediatr. 2008;152: 276-80.

5. Murat-Sušić S, Husar K, Skerlev M, Marinović B, Babic I. Inherited epidermolysis bullosa - the spectrum of complications. Acta Dermatovenerol Croat. 2011;19:255-63.

6. Boeira VLSY, Souza ES, Rocha BO, Oliveira PD, Oliveira MFSP, Rêgo VRPA Follador I. Inherited epidermolysis bullosa: clinical and therapeutic aspects. An Bras Dermatol. 2013;88:185-98.

7. Goldschneider KR, Good J, Harrop E, Liossi E, Lynch-Jordan A, Martinez A, et al. Pain care for patients with epidermolysis bullosa: best care practice guidelines. BMC Med. 2014;12:178-202.

8. Comer GC, Ladd AL. Management of complications of congenital hand disorders. Hand Clin. 2015;31:361-75.

9. Vowinkel T, Laukoetter M, Mennigen R, Hahnenkamp K, Gottschalk A, Boschin $\mathrm{M}$, et al. A two-step multidisciplinary approach to treat recurrent esophageal strictures in children with epidermolysis bullosa dystrophica. Endoscopy. 2015;47:541-4.

10. Montaudié H, Chiaverini C, Sbidian E, Charlesworth A, Lacour J-P. Inherited epidermolysis bullosa and squamous cell carcinoma: a systematic review of 117 cases. Orphanet J Rare Dis. 2016;11:117-29.

11. Kim M, Li M, Intong-Wheeler LRA, Tran K, Marucci D, Murrell DF. Epidemiology and outcome of squamous cell carcinoma in epidermolysis bullosa in Australia and New Zealand. Acta Derm Venereol. 2018;98:70-6.

12. Mellado F, Fuentes I, Palisson F, Vergara JI, Kantor A. Ophthalmologic approach in epidermolysis bullosa: a Cross-sectional study with phenotypegenotype correlations. Cornea. 2018;37:442-7.

13. Perdoni C, Osborn MJ, Tolar J. Gene editing toward the use of autologous therapies in recessive dystrophic epidermolysis bullosa. Transl Res. 2016;168:50-8.

14. El Hachem M, Zambruno G, Bourdon-Lanoy E, Ciasulli A, Buisson C, HadjRabia $S$, et al. Multicentre consensus recommendations for skin care in inherited epidermolysis bullosa. Orphanet J Rare Dis. 2014;9:76.

15. Siañez-González C, Pezoa-Jares R, Salas-Alanis JC. Congenital epidermolysis bullosa: a review. Actas Dermosifilogr. 2009;100:842-56.

16. Tabolli S, Pagliarello C, Uras C, Di PC, Zambruno G, Castiglia D, et al. Family burden in epidermolysis bullosa is high independent of disease type/ subtype. Acta Derm Venereol. 2010;90:607-11.

17. Van Scheppingen C, Lettinga AT, Duipmans JC, Maathuis KG, Jonkman MF The main problems of parents of a child with epidermolysis bullosa. Qual Health Res. 2008;18:545-56.

18. APA. American Psychological Association dictionary of Psychology. 2018 https://dictionary.apa.org/psychosocial. Accessed 20 Apr 2018. 
19. WHO. Measuring quality of life. Geneva; 1997. https://ink.springer.com/reference workentry/10.1007\%2F978-94-007-0753-5_3282. Accessed 1 Sept 2016.

20. Lazarus RS, Folkman S. Stress, appraisal, and coping. New York: Springer; 1984.

21. Dodge R, Daly AP, Huyton J, Sanders LD. The challenge of defining wellbeing. Int J Wellbeing. 2012;2:222-35.

22. The grading of recommendations assessment, development and evaluation. (c) 2004-2018 - the GRADE working group. 2016. http://www. gradeworkinggroup.org/- Accessed 15th Feb 2016.

23. Butterworth S, Mitchell A, Mason-Whitehead E, Martin K. Epidermolysis bullosa: how social support affects quality of life. Nurs Times. 2019;115:48-51.

24. Critical appraisal skills programme (CASP). 2017. Available at http://www. casp-uk.net/. Accessed 04 July 2017

25. The Scottish intercollegiate guidelines network (SIGN). 50 guideline Developer's handbook, NHS revised edition 2008.

26. Caldwell K, Henshaw L, Taylor G. Developing a framework for critiquing health research. J Health Social Environ Issues. 2005;6:45-54.

27. Brouwers M, Kho M, Browman G, Burgers J, Cluzeau F, Feder G, Fervers B, et al. AGREE next steps consortium. AGREE II: advancing guideline development, reporting and evaluation in healthcare. Can Med Assoc J. 2010; https://www.agreetrust.org/. Accessed 2 Aug 2018.

28. Horn HM, Tidman MJ. Quality of life in epidermolysis bullosa. Clin Exp Dermatol. 2002;27:707-10.

29. Pagliarello C, Tabolli S. Factors affecting quality of life in epidermolysis bullosa. Expert Rev Pharmacoeconomics Res. 2010;10:329-38.

30. Tabolli S, Sampogna F, Di Pietro C, Paradisi A, Uras C, Zotti P, et al. Quality of life in patients with epidermolysis bullosa. Br J Dermatol. 2009;161:867-77.

31. Schräder NHB, Yuen WY, Jonkman MF. Pain quality assessment scale for epidermolysis bullosa. Acta Derm Venereol. 2018;98:346-9.

32. Jain SV, Murrell DF. Psychosocial impact of inherited and autoimmune blistering diseases. Int J Womens Dermatol. 2018;4:49-53.

33. Dures E, Rumsey N, Morris M, Gleeson K. A cross sectional, observational survey to assess levels and predictors of psychological wellbeing in adults with epidermolysis bullosa. Health Psychol Res. 2013;1:16-20.

34. Williams EF, Gannon K, Soon K. The experiences of young people with epidermolysis bullosa simplex: a qualitative study. J Health Psychol. 2011;16:701-10.

35. Nading MA, Lahmar JJ, Frew JW, Ghionis N, Hanley M, Kemble Welch A, et al. A ski and adventure camp for young patients with severe forms of epidermolysis bullosa. J Am Acad Dermatol. 2009;61:508-11.

36. Cross Bodán R. Epidermolysis bullosa: an insider's perspective to a rare genetic connective tissue disorder. J Dermatol Nurses Assoc. 2016;8:46-56.

37. Van Scheppingen C, Lettinga AT, Duipmans JC, Maathuis CG, Jonkman MF. Main problems experienced by children with epidermolysis bullosa: a qualitative study with semi-structured interviews. Acta Derm Venereol. 2008;88:143-50.

38. Yuen WY, Duipmans JC, Jonkman MF. The needs of parents with children suffering from lethal epidermolysis bullosa. Br J Dermatol. 2012;167:613-8.

39. Janus C, Bhogal P. Skin Warriors': skin patients are often subjected to prejudice and regulations. Now they tell it like it is. Abilities. 2014:14-8. https://www.abilities.ca/uncategorized/skin-warriors/. Accessed 14 May 2019.

40. Adni T, Martin K, Mudge E. The psychosocial impact of chronic wounds on patients with severe epidermolysis bullosa. J Wound Care. 2012;21:528-63.

41. Soon K, Mason R, Price F, Martinez A, Mellerio JE. The psychological adjustment of children with epidermolysis bullosa and the differential effects of disease and psychosocial variables. Br J Dermatol. 2008;159(Suppl 1):115-6.

42. Brun J, Chiaverini C, Devos C, Leclerc-Mercier S, Mazereeuw J, Bourrat E, et al. Pain and quality of life evaluation in patients with localized epidermolysis bullosa simplex. Orphanet J Rare Dis. 2017;12:119.

43. Downe A. The effect of current economic cuts to wound dressings and its impact on patients with epidermolysis bullosa: a case study. Wounds UK. 2017;13:46-53.

44. Snauwaert JJL, Yuen WY, Jonkman MF, Moons P, Naulaers G, Morren MA. Burden of itch in epidermolysis bullosa. Br J Dermatol. 2014;171:73-8.

45. Fortuna G, Aria M, Cepeda-Valdes R, Garcia-Garcia SC, Moreno Trevino MG, Salas-Alanís JC. Role of dystrophic epidermolysis bullosa in anxiety, depression and self-esteem: a controlled cross-sectional study. J Dermatol. 2016:43:70-8.

46. Dures E, Morris M, Gleeson K, Rumsey N. The psychosocial impact of epidermolysis bullosa. Qual Health Res. 2011;21:771-82.

47. Feldmann R, Weglage J, Frosch M. Cognitive function in patients with epidermolysis bullosa: social adjustment and emotional problems. Klin Padiatr. 2012;224:22-5
48. Andreoli E, Mozzetta A, Angelo C, Paradisi M, Foglio Bonda PG. Epidermolysis bullosa. Psychological and psychosocial aspects. Dermatol Psychosom. 2002;3:77-81.

49. Gowran RJ, Kennan A, Marshall S, Mulcahy I, Ní Mhaille SN, Beasley S, et al. Adopting a sustainable Community of Practice Model when developing a service to support patients with epidermolysis bullosa: a stakeholdercentered approach. Patient. 2015;8:51-63.

50. Stevens LJ, McKenna S, Marty J, Cowin AJ, Kopecki Z. Understanding the outcomes of a home nursing programme for patients with epidermolysis bullosa: an Australian perspective. Int Wound J. 2016;13:863-9.

51. Macik D, Kowalska-Dabrowska M. The need of social support, life attitudes and life satisfaction among parents of children suffering from epidermolysis bullosa. Przegl Dermatol. 2015;102:211-20.

52. Fine JD, Johnson LB, Weiner $M$, Suchindran C. Impact of inherited epidermolysis bullosa on parental interpersonal relationships, marital status and family size. Br J Dermatol. 2005;152:1009-14.

53. Margari F, Lecce PA, Santamato W, Ventura P, Sportelli N, Annicchiarico G, et al. Psychiatric symptoms and quality of life in patients affected by epidermolysis bullosa. J Clin Psychol Med Settings. 2010;17:333-9.

54. Dietz MJ. A day in the life of a patient with DDEB. J Am Acad Dermatol. 2004;51:S59.

55. Lansdown R, Atherton D, Dale A, Sproston S, Lloyd J. Practical and psychological problems for parents of children with epidermolysis bullosa. Child Care Health Dev. 1986;12:251-6.

56. Dures E, Morris M, Gleeson K, Rumsey N. 'You're whatever the patient needs at the time': the impact on health and social care professionals of supporting people with epidermolysis bullosa. Chronic IIIn. 2010;6:215-27.

57. Frew JW, Murrell DF. Quality of life measurements in epidermolysis bullosa: tools for clinical research and patient care. Dermatol Clin. 2010;28:185-90.

58. Foster $L$, Holmes $Y$. Transition from paediatric to adult service in epidermolysis bullosa. Br J Nurs. 2007;16:244-6.

59. Goldschneider KR, Lucky A. Pain management in epidermolysis bullosa. Dermatol Clin. 2010:28:273-82.

60. Coakley R, Wihak T. Evidence-based Psychological interventions for the Management of Pediatric Chronic Pain: new directions in research and clinical practice. Children (Basel). 2017;4:9.

61. Fisher E, Heathcote L, Palermo TM, de C Williams AC, Lau J, Eccleston C. Systemic review and meta-analysis of psychological therapies for children with chronic pain. J Pediatr Psychol. 2014;39:763-82.

62. Markozannes G, Aretouli E, Rintou E, Dragioti E, Damigos D, Ntzani E, et al. An umbrella review of the literature on the effectiveness of psychological interventions for pain reduction. BMC Psychol. 2017:5:31-47.

63. Morley S, Williams A, Eccleston C. Examining the evidence about psychological treatment for chronic pain: time for a paradigm shift? Pain. 2013;154:1929-31.

64. The British Pain Society. Guidelines for Pain Management Programmes for adults. London: The British Pain Society; 2013. https://www. britishpainsociety.org/static/uploads/resources/files/pmp2013_main_FINAL_ v6.pdf. Accessed 27 July 2018.

65. Pilo C. Life with epidermolysis bullosa perception and experience of people living with EB and their caregivers: DEBRA Italy. Brief presentation of results. Zagreb: Debra International congress; 2016. 23rd September 2016. http:// www.debra-international.org/fileadmin/media_data/4_DEBRA_International/ 2 Events/2016 DI Congress_Zagreb/The voice of people_living with EB_-_Cinzia_Pilo.pdf. Accessed 13 Mar 2018.

66. Brenko I. Family gathering newsletter. DEBRA Croatia website 2017; www. debra.hr. Accessed 25 Aug 2017.

67. Pérez Matta F. Estudio Psicosocial de Pacientes con EB en Chile: Una aproximación a la realidad cotidiana de nuestros niños: DEBRA Chile. Santiago: Presentation at IX Simposio Internacional de Epidermolisis Bulosa; 2016.

68. Sebaratnam DF, Frew JW, Davatchi F, Murrell DF. Quality of life measurement in blistering diseases. Dermatol Clin. 2012;30:301-7.

69. Lynch-Jordan A. Parenting an EB patient. Cincinnati: Presentation at DEBRA congress; 2012.

70. Budych K, Helms TM, Schultz C. How do patients with rare diseases experience the medical encounter? Exploring role behaviour and its impact on patient-physician interaction. Health Policy. 2012;105:154-64.

71. Moss K. Contact at the borderline: psychoanalytic psychotherapy with EB patients. Br J Nurs. 2008:17:449-55. 